\title{
Cost Effectiveness of Paliperidone Long-Acting Injectable Versus Other Antipsychotics for the Maintenance Treatment of Schizophrenia in France
}

\author{
Sylvain Druais ${ }^{1}$ Agathe Doutriaux ${ }^{2} \cdot$ Magali Cognet $^{2} \cdot$ Annabelle Godet $^{3}$. \\ Christophe Lançon $^{4} \cdot$ Pierre Levy $^{5} \cdot$ Ludovic Samalin $^{6} \cdot$ Pascal Guillon $^{3}$
}

Published online: 16 February 2016

(c) The Author(s) 2016. This article is published with open access at Springerlink.com

\begin{abstract}
Background French clinical recommendations suggest prescribing long-acting injectable (LAI) antipsychotics to patients with a maintenance treatment indication in schizophrenia. Despite this, and due to their relatively high acquisition and administration costs, LAIs are still underused in clinical practice in France, thus highlighting the need for pharmacoeconomic evaluations.

Objective Our objective was to estimate the cost effectiveness of paliperidone LAI (or paliperidone palmitate), a once-monthly second-generation LAI antipsychotic, compared with the most common antipsychotic medications for the maintenance treatment of schizophrenia in France.

Methods A Markov model was developed to simulate the progression of a cohort of schizophrenic patients through four health states (stable treated, stable non-treated, relapse and death) and to consider up to three lines of treatment to account for changes in treatment management. Paliperidone LAI was compared with risperidone LAI, aripiprazole LAI, olanzapine LAI, haloperidol LAI (or haloperidol decanoate) and oral olanzapine. Costs, quality-adjusted
\end{abstract}

Sylvain Druais

sylvain.druais@gmail.com

1 Amaris, 204 rue du Saint-Sacrement, Espace Rezomont 3ième étage, Montréal QC H2Y 1W8, Canada

2 Amaris, London, UK

3 Janssen Cilag, Issy-les-Moulineaux, France

4 Faculty of Medicine of Marseille, Marseille, France

5 University of Paris-Dauphine, Paris, France

6 CHU Clermont-Ferrand, University of Auvergne, EA 7280 Clermont-Ferrand, France life-years (QALYs) and number of relapses were assessed over 5 years based on 3-month cycles with a discount rate of $4 \%$ and from a French health insurance perspective. Patients were considered to be stabilised after a schizophrenic episode and would enter the model at an initiation phase, followed by a prevention of relapse phase if successful. Data (e.g. relapse or discontinuation rates) for the initiation phase came from randomised clinical trials, whereas relapse rates in the prevention phase were derived from hospitalisation risks based on real-life French data to capture adherence effects. Safety and utility data were derived from international publications. Additionally, costs were retrieved from French health insurance databases and publications. Finally, expert opinion was used for validation purposes or in case of gaps in data. The robustness of results was assessed through deterministic and probabilistic sensitivity analyses.

Results All LAI antipsychotics were found to have similar costs over 5 years: approximatively $€ 55,000$, except for paliperidone LAI which had a discounted cost of $€ 50,880$. Oral olanzapine was less costly than LAIs (i.e. $€ 50,379$ after 5 years) but was associated with fewer QALYs gained and relapses avoided. Paliperidone LAI dominated aripiprazole LAI, olanzapine LAI and haloperidol LAI in terms of costs per QALY, and it was associated with slightly fewer QALYs when compared with risperidone LAI (i.e. 3.763 vs 3.764). This resulted in a high incremental cost-effectiveness ratio (ICER) (i.e. $€ 4,770,018$ per QALY gained) for risperidone LAI compared with paliperidone LAI. Paliperidone LAI was more costly than olanzapine oral but associated with more QALYs (i.e. ICER of $€ 2411$ per QALY gained for paliperidone LAI compared with oral olanzapine). Paliperidone LAI had a probability of being the optimal strategy in more than $50 \%$ of cases for a willingness-to-pay threshold of $€ 8000$ per QALY gained. 
Conclusion This analysis, to the best of our knowledge, is the first of its kind to assess the cost effectiveness of antipsychotics based on French observational data. Paliperidone LAI appeared to be a cost-effective option in the treatment of schizophrenia from the French health insurance perspective.

\section{Key Points for Decision Makers}

Risperidone long-acting injectable (LAI) and paliperidone LAI were associated with the most discounted quality-adjusted life-years (QALYs) over 5 years (i.e. 3.764 and 3.763, respectively), with paliperidone LAI less costly than risperidone LAI, resulting in an incremental cost-effectiveness ratio (ICER) of $€ 4,770,018$ per QALY gained for risperidone LAI compared with paliperidone LAI. Paliperidone LAI dominated aripiprazole LAI, olanzapine LAI and haloperidol LAI, and was associated with an ICER of $€ 2411$ per QALY gained compared with olanzapine oral.

In the probabilistic sensitivity analysis, for any threshold, paliperidone LAI was associated with the highest probability of being the optimal strategy in comparison with all other strategies simultaneously in terms of QALYs gained and relapses avoided.

The present analysis suggests that paliperidone LAI is a cost-effective treatment for patients with schizophrenia in France. However, the study also highlights the scarcity of available data, especially on long-term efficacy.

\section{Introduction}

Schizophrenia is a severe mental disorder characterised by deep disruptions in thinking, language, perception, and sense of self [1]. The various symptoms can be classified into two main categories: 'positive' symptoms (such as delusions, hallucinations, disorganized speech and catatonic behaviour) and 'negative' symptoms (such as blunted affect and alogia) [2, 3]. The course of the disease varies widely and, in the majority of cases, patients experience alternating periods of remission and recurrence, with unpredictable patterns of symptoms $[4,5]$. The pathology leads to a decrease in functional capacity [6], and is associated with a broad range of psychosocial difficulties such as unemployment, loneliness and housing issues [7].
All of the above substantially affect quality of life and wellbeing. Those with schizophrenia face a mortality risk that is more than double that of the general population, a statistic that is predominantly due to the high rate of suicides, cardiovascular diseases, and metabolic and infectious afflications [1].

According to the World Health Organization (WHO), schizophrenia is one of the most concerning pathologies of the twenty-first century, affecting more than 21 million people worldwide, and ranks as the 14th cause of disability in the world [8, 9]. In France, schizophrenia is estimated to affect between 300,000 and 600,000 people, with an incidence of 10,000 new patients per year [10-12]. The public health and financial burdens of schizophrenia are recognised to be substantial by the French authorities (e.g. patients affected by schizophrenia represent the largest group of hospitalised patients in public institutions and specialised centres in France) [3, 7, 13-15]. According to the French Ministry of Health, improvement in the healthcare management of patients with mental disorders, and especially the prevention and reduction of the risk of relapse through the enhancement of patient follow-up and quality of life, is a major public health concern [9].

Despite the increase in interest in the management of schizophrenia, information regarding the current treatment landscape remains unclear. The lack of treatment compliance is an area of concern that can be difficult to accurately quantify. Long-term clinical trials may include biases in terms of observance due to reinforced monitoring and close management of the patients inherent to the protocol. Although observational studies are often more apt to reflect the behaviour of patients in a real-life setting, data are limited.

Moreover, the superiority of second-generation versus first-generation antipsychotics has not been clearly demonstrated as part of clinical trials and is still a controversial topic [16-18]. Given this, in 2011, the French National Health Agency (Haute Autorité de Santé [HAS]) decided to re-evaluate the safety and efficacy of secondgeneration oral antipsychotics compared with the firstgeneration variants [19]. The HAS and most evidencebased guidelines for the maintenance treatment of schizophrenia recommend long-acting injectable (LAI) antipsychotics to be used predominantly in the prevention of relapse for non-compliant patients. Some consensusbased guidelines recommend the use of LAIs as a first-line treatment for most patients who require long-term antipsychotics [20, 21]. Furthermore, the difference in clinical and economic benefits between oral and LAI forms have not yet been clearly established [22, 23].

Few economic studies have been conducted in France assessing either the costs associated with schizophrenia or the benefit/costs ratio of antipsychotics [24, 25]. In 2005, a French study comparing three antipsychotics established 
superiority with LAI risperidone compared with LAI haloperidol and oral olanzapine [25]. Since 2005, three LAI antipsychotics have received a European marketing authorisation (MA): olanzapine LAI (Zypadhera ${ }^{\circledR}$, MA in 2008), paliperidone LAI (Xeplion ${ }^{\circledR}$, MA in 2011) and aripiprazole LAI (Abilify Maintena ${ }^{\circledR}$, MA in 2013). To our knowledge, no recently published studies have compared the cost impact and health benefits of these treatments in France.

Using an original pharmacoeconomic model and reallife French data on hospitalisation [26], we sought to assess the cost effectiveness of the most relevant pharmaceutical maintenance treatment options in the management of schizophrenia in France for patients stabilised after a schizophrenic episode.

\section{Materials and Methods}

\subsection{Overview}

A model was developed following the French HAS guidelines for health economic studies (see Appendix Table 9) [27]. Second-generation LAI antipsychotics approved in France, most prescribed first-generation LAIs and oral second-generation antipsychotics were identified and validated by clinical experts. ${ }^{1,2}$ These included paliperidone LAI, risperidone LAI, aripiprazole LAI, olanzapine LAI, haloperidol LAI and oral olanzapine. Costs, quality-adjusted life-years (QALYs) gained and relapses avoided were assessed and compared for each of these compounds over a time horizon of 5 years at a discount rate of $4 \%$, from a French statutory health insurance perspective ('Assurance Maladie' [25]).

An health economic expert validated the approach by ensuring that the methodology aligned with French guidelines, international guidelines and economic theory. ${ }^{3}$

Relapse rates were derived from hospitalisation risks from a French observational study: the CGS (Cohort for the General study of Schizophrenia) [26]. The patient pathway for each assessed treatment in the model was split into two main steps (Fig. 1) to account for changes in healthcare management between the initiation and prevention phases of the treatment (e.g. difference in antipsychotic doses, frequency of clinicians' consultations, hospitalisation duration for initiation, occurrence of adverse events, etc.).

\footnotetext{
${ }^{1}$ Pr Christophe Lançon (Faculty of Medicine of Marseille, Marseille, France) and Dr Ludovic Samalin (CHU Clermont-Ferrand, ClermontFerrand, France).

${ }^{2}$ Please note that each time the expert's opinion is mentioned, we refer to the experts reported in footnote 1 and/or 3.

${ }^{3}$ Pr Pierre Lévy (University of Paris-Dauphine, Paris, France).
}

\subsection{Markov Model}

In order to conserve enough flexibility while retaining a certain level of transparency, and based on previous published cost-effectiveness analyses of antipsychotics [23, 28, 29], an original Markov model structure was developed for our study. The robustness of the conclusions was tested in sensitivity analyses, and the results were compared with the published literature. This approach has been deemed appropriate for chronic diseases such as schizophrenia because it facilitates the modelling of recurrent events such as relapses. The model allowed the comparison of all interventions simultaneously, considering specific initiation phases for each of the comparators. The core model was run based on data for treatment efficacy and discontinuation rates, while sub-models ran in parallel, tracking adverse event occurrences (one sub-model by type of adverse event).

The Markov model simulated the progression of a cohort of adult schizophrenic patients, stabilised after a schizophrenic episode, through four main health states ('stable treated', 'stable non-treated', 'relapse' and 'death') and up to three lines of treatment over 5 years (Fig. 1). The model was developed using Microsoft ${ }^{\circledR}$ Excel, version 2010 (Microsoft Corporation, Redmont, WA, USA).

According to clinical opinion ${ }^{1}$, a cycle length of 3 months was considered appropriate to capture both clinical practice and the associated events such as relapses and adverse events. Patients entered the model after a 1-month stabilisation phase and initiated antipsychotic treatment at a specific dose (i.e. the initiation phase, shown in blue in Fig. 1). Stable patients who continue to receive the same therapy after the 3-month initiation phase progress to the prevention phase (i.e. in white in Fig. 1), otherwise patients discontinue treatment.

Over the prevention phase, patients could either progress to another health state because of a treatment discontinuation or remain in the same state. Three causes of treatment discontinuation were considered: (1) patients who relapsed due to lack of efficacy and progression to the 'relapse' health state (with or without a hospitalisation), (2) patients who switched due to medication intolerance and moved to the 'stable treated' health state in the initiation phase on the next line of antipsychotics, or (3) patients who interrupted their antipsychotic treatment based on personal choice, were lost to follow-up or other reasons, and transitioned to the 'stable non-treated' health state. At each cycle, patients could move to the health state 'death' from any state.

\subsection{Therapeutic Sequence}

The treatment sequence consisted of three lines of antipsychotics (Fig. 2). In accordance with French guidelines [30], 
Fig. 1 Markov model structure. The CGS (Cohort for the General study of Schizophrenia) is a French observational study that aimed to compare the impacts of risperidone LAI with other antipsychotics in terms of hospitalisation rates. At each cycle, patients could move to the health state 'death' from any state (not represented here). AEs adverse events, $A P n$ antipsychotic, Hospi hospitalisation, LAI long-acting injectable

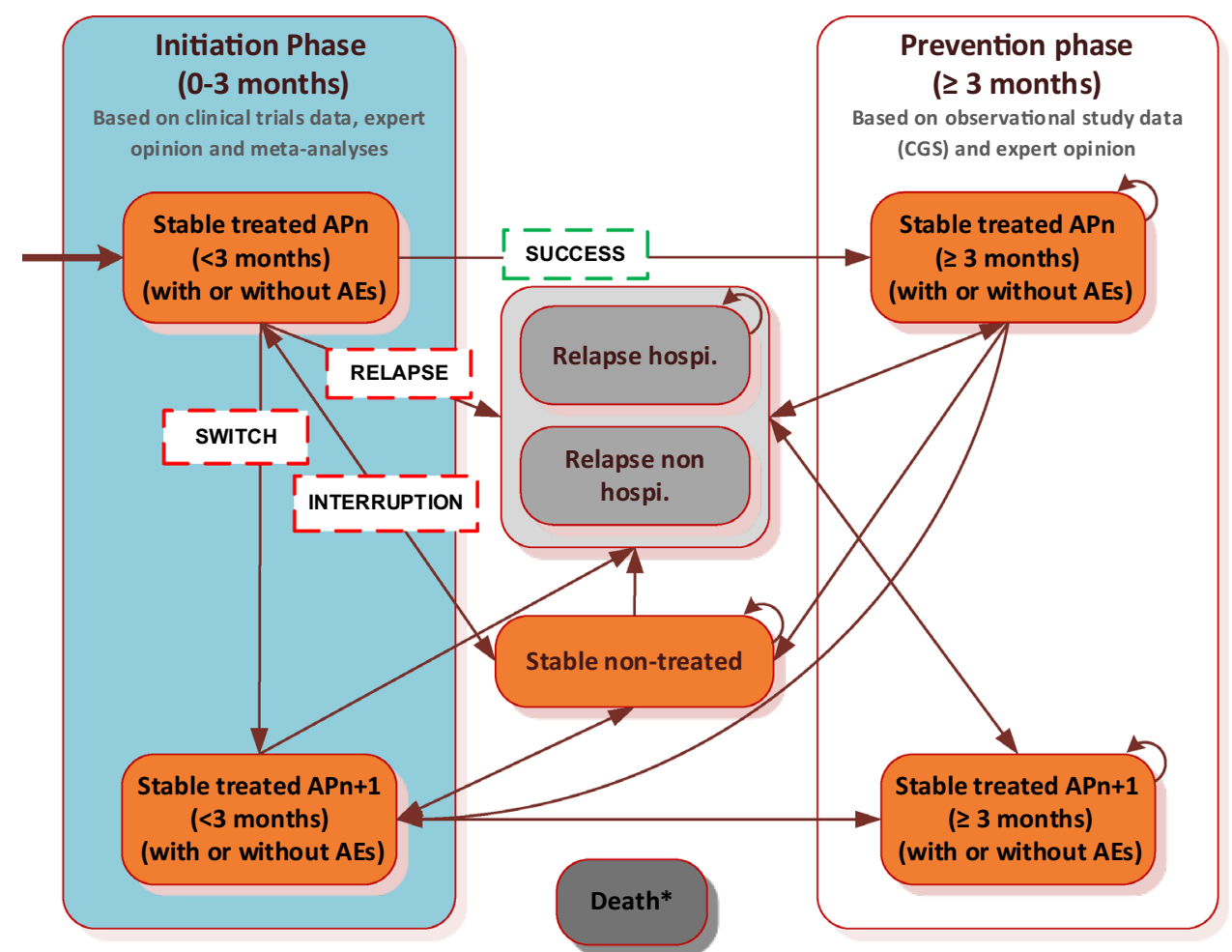

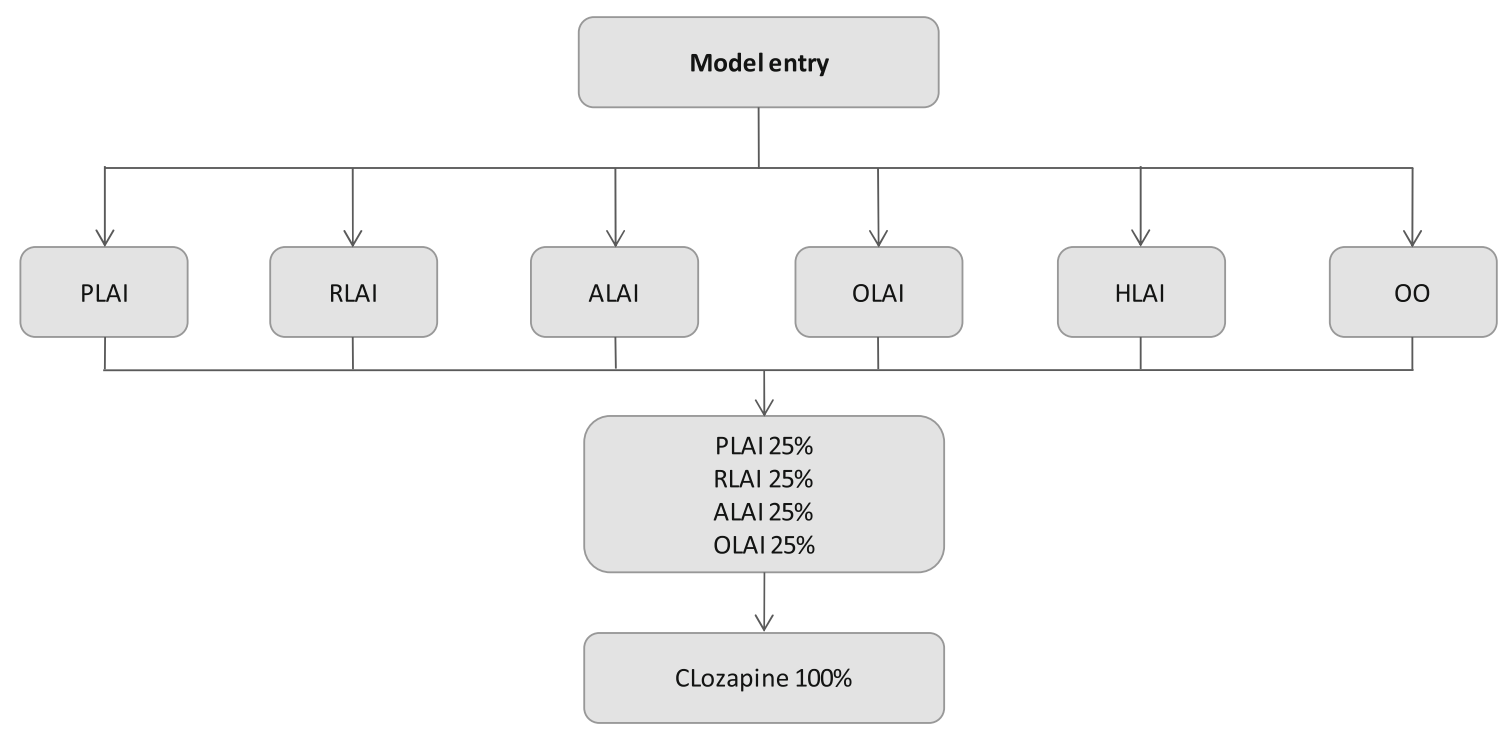

Fig. 2 The treatment sequence. $A L A I$ aripiprazole long-acting injectable, $H L A I$ haloperidol long-acting injectable, $O L A I$ olanzapine long-acting injectable, $O O$ oral olanzapine, $P L A I$ paliperidone long-acting injectable, $R L A I$ risperidone long-acting injectable

which recommend second-generation LAI antipsychotics as the first-line maintenance treatment for patients with schizophrenia, patients in the model could receive any of the four second-generation LAIs licensed in France (i.e. paliperidone LAI, risperidone LAI, aripiprazole LAI and olanzapine LAI) [31-34]. To compare these with other classes of antipsychotics still available on the French market, we also included the most prescribed typical LAI and oral antipsychotic (haloperidol LAI, $42 \%$ of the typical LAIs in France [26, 35]; and olanzapine oral, $31 \%$ of oral antipsychotics in France [26, 36]). As the objective was to assess the cost effectiveness of initial treatment, subsequent treatment lines were assumed to be independent of the initial line and similar across assessed treatments. Based both on French clinical guidelines [30] and on expert opinion, the second-line treatment included second-generation LAI 
Table 1 Mean doses of antipsychotics used in the model

\begin{tabular}{llll}
\hline & Initiation phase & Prevention phase & Sources \\
\hline PLAI & $150 \mathrm{mg}$ on D1; $100 \mathrm{mg}$ on D8 & $75 \mathrm{mg}$ monthly & Xeplion ${ }^{\circledR}$ SmPC [32] \\
RLAI & $37.5 \mathrm{mg} / 2$ weeks ${ }^{\mathrm{a}}$ & $37.5 \mathrm{mg} / 2$ weeks & RisperdalConsta ${ }^{\circledR}$ SmPC [31] \\
ALAI & $400 \mathrm{mg}$ monthly & $400 \mathrm{mg}$ monthly & Abilify Maintena ${ }^{\circledR}$ SmPC [34] \\
OLAI & $300 \mathrm{mg} / 2$ weeks & $210 \mathrm{mg} / 2$ weeks & Zypadhera ${ }^{\circledR}$ SmPC [33] \\
HLAI & $5 \mathrm{ml} \mathrm{per} \mathrm{injection}$ & $5 \mathrm{ml} \mathrm{per} \mathrm{injection}$ & Haldol Decanoas $^{\circledR}$ SmPC [35] \\
OO & $10 \mathrm{mg} /$ day & $10 \mathrm{mg} /$ day & Zyprexa ${ }^{\circledR}$ SmPC [36] \\
Clozapine & $300 \mathrm{mg} /$ day & $300 \mathrm{mg} /$ day & Clozapine SmPC [54] \\
\hline
\end{tabular}

$A L A I$ aripiprazole long-acting injectable, $D x$ day $x$, HLAI Haloperidol long-acting injectable, OLAI olanzapine long-acting injectable, $O O$ oral olanzapine, $P L A I$ paliperidone long-acting injectable, RLAI risperidone long-acting injectable, $S m P C$ summary of product characteristics

a The recommended dose of RLAI was $25 \mathrm{mg}$ in the SmPC, but the equivalent dose to be compared with paliperidone LAI was $37.5 \mathrm{mg}$. We decided, based on clinical expert opinion, to use risperidone LAI at $37.5 \mathrm{mg} / 2$ weeks in the analyses antipsychotics. Thus, clinical and economic inputs were elicited by a weighted average in equal proportions of data for paliperidone LAI $(25 \%)$, risperidone LAI $(25 \%)$, aripiprazole LAI $(25 \%)$ and olanzapine LAI $(25 \%)$. Clozapine was prescribed as the last treatment line according to international clinical guidelines ${ }^{4}$ [37].

The antipsychotic doses were as per Summary of Product Characteristics (SmPC) recommendations (Table 1).

\subsection{Model Parameters and Assumptions}

Input parameters were derived from an observational study (i.e. CGS) [26], clinical trials [38, 39], relevant literature $[40,41]$ and assumptions based on expert opinions. We conducted a literature review (until 2014) through MEDLINE $^{\circledR}$ and MEDLINE-In-Process ${ }^{\circledR}$ databases, focusing on meta-analyses results for efficacy, safety and discontinuation rates for the different comparators. Relevant terms for the pathology were combined with appropriate study types, interventions and outcomes. The electronic search was restricted to English and French publications. Additional ad hoc searches were conducted to complete information on standardised mortality rate (SMR) by health state and utility, as well as hospitalisation costs, treatment costs and treatment-related adverse event costs in France (with an update for treatment costs in 2015). When data were lacking from published literature, expert opinion was sought through advisory panels and questionnaires.

\subsubsection{Demographic Characteristics}

Demographic characteristics were based on the CGS [26], where $68 \%$ of patients were male and the mean age was 38 years.

\footnotetext{
$\overline{4}$ Related to treatment-resistant schizophrenia: "Strongly consider clozapine after two unsuccessful antipsychotic trials" (Stahl et al [37]).
}

The CGS aimed to compare risperidone LAI with other antipsychotics and the impact on hospitalisation rates in real-life settings in France [26]. This study followed 1859 patients diagnosed with schizophrenia over a mean period of 12 months and found that patients treated with risperidone LAI had lower rates of hospitalisation than those receiving other antipsychotics.

\subsubsection{Transition Probabilities}

In the initiation phase, transition probabilities were derived from the phase III clinical trial PSY-3006 assessing the efficacy and safety of paliperidone LAI versus risperidone LAI over 13 weeks (i.e. patient follow-up and monitoring environment closer to trial conditions) [39]. Following clinical opinion, we applied the assumption that the relative risk of treatment discontinuation in the initial phase was comparable between oral and injectable forms; for other injectable antipsychotics (i.e. aripiprazole LAI, olanzapine LAI and haloperidol LAI), odds ratios (ORs) from the meta-analysis by Leucht et al. [40] were derived from the oral forms (calculation detailed in Table 2). It was assumed that the risk of relapse, switch and interruption for oral olanzapine was similar to those for olanzapine LAI in the initiation phase (i.e. noninferiority analyses showed comparable efficacy between oral and LAI in the initiation phase, in which the close follow up of patients ensures a certain level of compliance irrespective of treatment form) [42-44].

In the prevention phase, the risks of relapse were derived from real-life data (i.e. CGS; data allowing the capture of adherence effects) when available [26]. The hospitalisation rate from the CGS was chosen to estimate the relapse rate based on the conclusion from Olivares et al. [45], who demonstrated that hospitalisation was the most frequently used factor to track the incidence of relapse. In the CGS, the annual risk of hospitalisation, readjusted for treatment 
Table 2 Three-month probabilities of treatment discontinuation (i.e. relapse, switch and interruption)

\begin{tabular}{|c|c|c|c|c|c|c|c|c|}
\hline Items & PLAI & RLAI & ALAI & OLAI & HLAI & $\mathrm{OO}$ & Clozapine & Sources \\
\hline \multicolumn{9}{|c|}{ 3-month probability of relapse ${ }^{a}$} \\
\hline IP & $0.0659[39]$ & $0.0701[39]$ & $0.0820[40]$ & $0.0640[40]$ & $0.1052[40]$ & $0.0640^{\mathrm{d}}[40]$ & $0.1158^{\mathrm{e}}$ & $\begin{array}{l}\text { RCT for PLAI and RLAI [39], and } \\
\text { meta-analysis for other } \\
\text { comparators [40] }\end{array}$ \\
\hline PP & $0.0825^{\mathrm{f}}$ & $0.0825[26]$ & $0.0825^{\mathrm{f}}$ & $0.0825^{\mathrm{f}}$ & $0.1810[26]$ & $0.1532[26]$ & $0.1158[72]$ & $\begin{array}{l}\text { Observational data for all } \\
\text { comparators [26], meta-analysis } \\
\text { vs. OO for clozapine [72] }\end{array}$ \\
\hline \multicolumn{9}{|c|}{ 3-month probability of $\operatorname{switch}^{\mathrm{b}}$} \\
\hline IP & $0.0329[39]$ & $0.0163[39]$ & $0.0413[40]$ & $0.0320[40]$ & $0.0537[40]$ & $0.0320^{\mathrm{d}}$ & $0.0048^{\mathrm{e}}$ & $\begin{array}{l}\text { RCT for PLAI and RLAI [39], and } \\
\text { meta-analysis for other } \\
\text { comparators [40] }\end{array}$ \\
\hline $\mathrm{PP}$ & $0.0042[38]$ & $0.0042^{\mathrm{g}}$ & $0.0042^{\mathrm{g}}$ & $0.0042^{\mathrm{g}}$ & $0.0042^{\mathrm{g}}$ & $0.0042^{\mathrm{g}}$ & $0.0048[72]$ & $\begin{array}{l}\text { RCT for PLAI [38], meta-analysis } \\
\text { vs. OO for clozapine [72] }\end{array}$ \\
\hline \multicolumn{9}{|c|}{ 3-month probability of interruption ${ }^{\mathrm{c}}$} \\
\hline IP & $0.1450[39]$ & $0.1452[39]$ & $0.1767[40]$ & $0.1412[40]$ & $0.2203[40]$ & $0.1412^{\mathrm{d}}$ & $0.0230^{\mathrm{e}}$ & $\begin{array}{l}\text { RCT for PLAI and RLAI [39], and } \\
\text { meta-analysis for other } \\
\text { comparators [40] }\end{array}$ \\
\hline $\mathrm{PP}$ & $0.0387[38]$ & $0.0387^{\mathrm{g}}$ & $0.0387^{\mathrm{g}}$ & $0.0387^{\mathrm{g}}$ & $0.0387^{\mathrm{g}}$ & $0.0387^{\mathrm{g}}$ & $0.0230[72]$ & $\begin{array}{l}\text { Hough et al. [38] } \\
\text { Haro et al. [72] }\end{array}$ \\
\hline
\end{tabular}

Formula applied for probabilities derived from OR: $p_{\mathrm{XLAI}}=\frac{p_{\mathrm{PLAI}} \times\left(\frac{1}{\mathrm{OR}}\right)}{\left(1-p_{\mathrm{PLAI}}\right)+\left(p_{\mathrm{PLAI}} \times\left(\frac{1}{\mathrm{OR}}\right)\right)}$

$A L A I$ aripiprazole long-acting injectable, $H L A I$ haloperidol long-acting injectable, $I P$ Initiation phase, $O L A I$ olanzapine long-acting injectable, $O O$ oral olanzapine, $O R$ odds ratio, $P L A I$ paliperidone long-acting injectable, $P P$ prevention phase, $R C T$ randomised controlled trial, $R L A I$ risperidone long-acting injectable, $S m P C$ summary of product characteristics

${ }^{a}$ Due to lack of efficacy

${ }^{b}$ Due to lack of tolerance

${ }^{c}$ Due to patient choice, loss to follow-up and other reasons

d Assumed equal to olanzapine LAI

e Probabilities assumed to be similar for clozapine in initiation and in prevention phase

${ }^{\mathrm{f}}$ Assumed equal to risperidone LAI

g Assumed equal to paliperidone LAI

effects and hospitalisation history associated with risperidone LAI, was $19.43 \%^{5}$ (assuming two-thirds of relapsing patients were hospitalised ${ }^{6}[25,28]$, resulting in an annual risk of relapse of $29.15 \%$ ). Thus, the 3-monthly risk of relapse for patients treated with risperidone LAI was estimated at $8.25 \%$ in the model. In case of relapse requiring

\footnotetext{
$\overline{5}$ Based on a global hospitalisation rate of 53/100 patient-years readjusted according to the hospitalisation history (i.e. OR 2.97 between risperidone LAI and other antipsychotics) and a relative annual risk of hospitalisation of risperidone LAI versus other antipsychotics of 0.66 , the readjusted hospitalisation rate for risperidone LAI was $44.3 / 100$ patient-years. This rate was then divided by the annual average number of hospitalisations (i.e. 2.05/year). Finally, the annual risk of hospitalisation was derived based on the proportional hazard assumption (i.e. risk $=1-\exp$ ['rate-time']).

${ }^{6}$ Based on Llorca et al. 2005 [25], in which it was assumed that $60 \%$ of French patients had a complete hospitalisation in case of lack of response, and Mehnert et al. 2012 [28], in which it was assumed that $63 \%$ of patients who had relapsed had been admitted to hospital during the 6-month observation period.
}

hospitalisation, the probabilities of leaving the hospital were time dependent and were derived from real-life data from the CHU Clermont-Ferrand [46]. Finally, in the prevention phase, the probability of discontinuation due to treatment interruption and lack of tolerance was derived from the intent-to-treat (ITT) population in the clinical trial PSY3001 (calculation detailed in Table 2), assessing paliperidone LAI over 52 weeks [38]. This study aimed to evaluate the efficacy and tolerability of paliperidone LAI in delaying 'time to relapse' in adults with schizophrenia.

\subsubsection{Clinical Assumptions}

We assumed that, after a relapse, two-thirds of patients were managed in a hospital setting whilst the remainder were treated in an outpatient care setting. This assumption was based on the recommendations of clinical experts. Patients were not allowed to move from the relapse 
requiring a hospitalisation' state to 'relapse without hospitalisation' or vice versa. Based on the mean interruption rates reported in PSY-3006 (i.e. patient's choice, lost to follow-up and other reasons [38]), we assumed that the proportion of patients who restarted the same antipsychotic after a relapse was $15 \%$. We also assumed that patients initiated their new antipsychotic treatment during the relapse phase (i.e. either at the hospital or in the outpatient setting) and then progressed directly to the prevention phase in the health state 'stable treated'.

Product labelling recommended LAI antipsychotics for previously stable patients [31-35]. In an international naturalistic study (RODOS [risperidone olanzapine drug outcomes studies in schizophrenia]) that included 1901 patients with schizophrenia, 548 of whom were from French centres and who received either olanzapine or risperidone, the median time to discharge from hospital for patients receiving risperidone and olanzapine was estimated to be 32 days and 37 days, respectively (with an average adjusted number of days at hospital of 27.3 and 31.3 , respectively) [47]. Thus, all patients in relapse had a 1-month stabilisation phase followed by an additional period of hospitalisation specific for each new antipsychotic (which was similar in the initiation phase). LAI antipsychotics without oral supplementation (i.e. paliperidone LAI, olanzapine LAI and haloperidol LAI) were associated with an additional week of hospitalisation to finalise the treatment initiation. Patients initiating an LAI antipsychotic with an oral supplementation were assumed to stay at the hospital until the end of their supplementation phase (i.e. 2 additional weeks for risperidone LAI and aripiprazole LAI). Patients who were initiated with an oral antipsychotic (i.e. olanzapine oral and clozapine) had a stabilisation phase of 1 month (i.e. assume no additional time of hospitalisation to initiate the treatment, based on clinical opinion). In the case of relapse without hospitalisation, it was assumed that outpatients remained in relapse for 1 month, based on the duration of relapse without hospitalisation estimated at 30 days by Mehnert et al. [28], thus $100 \%$ of patients moved after 3 months [28].

When patients switched due to drug intolerance, the next antipsychotic was initiated at the hospital in $10 \%$ of cases and in outpatient care for the others. Based on expert opinion, clozapine was initiated within a hospital setting for $90 \%$ of cases.

All patients who interrupted their treatment and did not relapse after one cycle were assumed to remain stable without treatment (one-third of patients), reinitiate the same antipsychotic (one-third of patients) or move to the next line of therapy in the initiation phase (one-third of patients). Based on expert opinion, we assumed a similar rate of treatment interruption for the other LAI antipsychotics of interest and that olanzapine oral was equivalent to olanzapine LAI (Table 2) [43].

\subsubsection{Mortality Rates}

Different probabilities of death were applied to stable patients and to patients in relapse. Mortality rates for stable patients were derived from a meta-analysis based on 37 studies over 25 countries, including France [48-50]. The median SMR for all-cause mortality in schizophrenia was 2.58 (3.02 for men and 2.37 for women) and was used in the model for stable patients. Mortality rates applied to patients in relapse were derived from SMR values in the year following hospital discharge from real-life data from patients with a principal diagnosis of schizophrenia from an English hospital (i.e. SMR 6.2) [51].

\subsubsection{Adverse Events}

Four adverse events were included in the study: extrapyramidal symptoms (EPS), tardive dyskinesia (TD), weight gain (WG) and diabetes. These adverse events were identified by experts as both clinically and economically relevant. Adverse events were considered individually, and each adverse event was assigned a specific duration: i.e. TD, WG and diabetes were assumed to be permanent within the time horizon (5 years), whereas the duration of EPS was assumed to be 3 months (one cycle), based on expert opinion. Permanent adverse events of interest were counted cumulatively. Patients with EPS were assumed to have the same probability of experiencing EPS at each cycle, regardless of treatment phase (Table 3). We assumed the safety profile of oral forms was similar to that for LAI forms [43].

\subsubsection{Utility}

The HAS recommends the use of French empirical data of preference scores but allows data from other countries if none are available in the French context [27]. Utility data were derived from a British study based on a time trade-off technique conducted in 49 stable patients with schizophrenia and 75 lay persons [41]. Health state utilities and utility decrement associated with side effects are presented in Table 4.

\subsubsection{Costs and Resource Utilisation}

Resource unit costs were expressed in $€$, December 2014 values. All costs were adjusted when necessary using the consumer price index (CPI) for health goods and services up to December 2014 [52]. 
Table 3 Three-month probabilities of adverse events (in percentage) ${ }^{\mathrm{a}}$

\begin{tabular}{|c|c|c|c|c|c|c|c|c|c|}
\hline $\begin{array}{l}\text { Risk of } \\
\text { adverse } \\
\text { event }^{\mathrm{a}}\end{array}$ & Phase & PLAI $(\%)$ & RLAI $(\%)$ & $\operatorname{ALAI}(\%)$ & OLAI $(\%)$ & HLAI $(\%)$ & $\mathrm{OO}(\%)$ & $\begin{array}{l}\text { Clozapine } \\
(\%)\end{array}$ & Sources \\
\hline \multirow[t]{2}{*}{ EPS } & IP & $5.50[32]$ & $5.50[31]$ & $3.53[16]$ & $3.21[16]$ & $13.28[16]$ & $3.21[16]$ & $0.98[16]$ & $\begin{array}{l}\text { SmPC for PLAI [32] and } \\
\text { RLAI [31], meta-analysis } \\
\text { for others [16] }\end{array}$ \\
\hline & PP & $5.50[32]$ & $5.50[31]$ & $3.53[16]$ & $3.21[16]$ & $13.28[16]$ & $3.21[16]$ & $0.98[16]$ & Similar to the initiation phase \\
\hline \multirow[t]{2}{*}{ TD } & IP & $0.17[39]$ & $0.16[39]$ & $0.17^{\mathrm{b}}$ & $0.00^{\mathrm{c}}$ & $2.28[17]$ & $0.00[17]$ & $0.00^{\mathrm{c}}$ & RCTs [17, 39] \\
\hline & $\mathrm{PP}$ & $0.00[73]$ & $0.00[31]^{\mathrm{b}}$ & $0.00[34]^{\mathrm{b}}$ & $0.00[33]^{\mathrm{b}}$ & $1.00[35]$ & $0.00[36]^{b}$ & $0.00^{\mathrm{c}}$ & $\begin{array}{l}\text { RCT for PLAI [73], SmPC } \\
\text { and assumptions for others } \\
{[31,33-36]}\end{array}$ \\
\hline \multirow[t]{2}{*}{ WG } & IP & $5.50[32]$ & $5.50[31]$ & $5.50[34]$ & $46.80[33,74]$ & $5.50[35]$ & $46.80^{\mathrm{d}}$ & $5.50[54]$ & $\begin{array}{l}\text { RCTs for OLAI [74], SmPC } \\
\text { for others }[31,32,34,35 \text {, } \\
54]\end{array}$ \\
\hline & $\mathrm{PP}$ & $1.47[38]$ & $1.47^{\mathrm{b}}$ & $1.47^{\mathrm{b}}$ & $10[33]$ & $\begin{array}{l}7.24[35 \\
72]\end{array}$ & $10[36]$ & $8.01[72]$ & $\begin{array}{l}\text { RCT [38] for PLAI, meta- } \\
\text { analysis for HLAI and } \\
\text { clozapine }[72], \text { SmPC for } \\
\text { others }[33,36]\end{array}$ \\
\hline \multirow[t]{2}{*}{ Diabetes } & IP & 0.00 & 0.00 & 0.00 & 0.00 & 0.00 & 0.00 & 0.00 & $\begin{array}{l}\text { Hypothesis: no diabetes in } \\
\text { instauration phase }\end{array}$ \\
\hline & $\mathrm{PP}$ & $0.55[32]$ & $0.55[31]$ & 1.00 [34] & $0.61[33]^{\mathrm{c}}$ & $0.47[75]$ & $0.61[75]$ & $0.00[54]$ & $\begin{array}{l}\text { Meta-analysis for HLAI and } \\
\text { OO [75], SmPC for others } \\
{[31,32,34,54]}\end{array}$ \\
\hline
\end{tabular}

$A L A I$ aripiprazole long-acting injectable, EPS extrapyramidal symptoms, HLAI haloperidol long-acting injectable, $I P$ initiation phase, $O L A I$ olanzapine long-acting injectable, $O O$ oral olanzapine, $P L A I$ paliperidone long-acting injectable, $P P$ prevention phase, $R C T$ randomised controlled trial, $R L A I$ risperidone long-acting injectable, $S m P C$ summary of product characteristics, $T D$ tardive dyskinesia, $W G$ weight gain

${ }^{a}$ When available, the risk of adverse events was derived from the SmPC, using the average value between the bounds of the provided interval; e.g. $\left.\mathrm{EPS}_{\mathrm{PLAI}}=(1 \%+10 \%) / 2=5.5 \%\right)$. In a conservative approach, the risk of diabetes for aripiprazole LAI was based on the inferior bound of the interval; i.e. $1 \%$

b Assumed equal to paliperidone LAI

c Assumed equal to olanzapine oral

d Assumed equal to olanzapine LAI

Table 4 Utility by health states and utility decrements associated with adverse events

\begin{tabular}{|c|c|c|}
\hline Health states & Mean utility & Sources \\
\hline \multicolumn{3}{|l|}{ Health state utility } \\
\hline Stable (no side effects) & 0.919 & Briggs et al. [41] \\
\hline Relapse (not requiring hospitalisation) & 0.762 & $\begin{array}{l}\text { Mid-point between utilities for stable } \\
\text { and relapse (requiring hospitalisation) }\end{array}$ \\
\hline Relapse (requiring hospitalisation) & 0.604 & Briggs et al. [41] \\
\hline Dead & 0.000 & \\
\hline \multicolumn{3}{|c|}{ Utility decrement associated with adverse events } \\
\hline Extrapyramidal symptom & -0.197 & Briggs et al. [41] \\
\hline Tardive dyskinesia & -0.197 & Assumed similar to extrapyramidal symptom \\
\hline Weight gain & -0.094 & Briggs et al. [41] \\
\hline Diabetes & -0.150 & Briggs et al. [41] \\
\hline
\end{tabular}

\subsubsection{Costs of Antipsychotic Medication Schizophrenia} is a chronic long-term illness, therefore treatment costs of schizophrenia are reimbursed at $100 \%$ by the statutory health insurance (SHI) in France [12]. Costs were based on the lowest public daily price with all taxes included and are published on the SHI website [53], with respect to the doses recommended by the SmPC [31-36, 54]. Generic drugs were used when available (Table 5). We assumed that, when patients were hospitalised, the antipsychotic medication costs were included in the daily hospitalisation costs, so no additional treatment costs were applied during the hospitalisation time. The treatment costs associated 
Table 5 Price of medicines

\begin{tabular}{|c|c|c|c|c|c|}
\hline Drug & $\begin{array}{l}\text { Price per } \\
\text { pack }(€)^{\mathrm{a}}[53]\end{array}$ & $\begin{array}{l}\text { Unit per } \\
\text { pack }\end{array}$ & Unit price $(€)$ & Cost per 3 months $(€)^{\mathrm{b}}$ & Comments/sources $[31-36,38]$ \\
\hline PLAI $150 \mathrm{mg}$ & 456.50 & 1 & $456.50[76]$ & Inpatient $^{\mathrm{c}}: 501$ & \multirow{2}{*}{$\begin{array}{l}\text { Initiation phase: PLAI } 150 \mathrm{mg} \text { at } \\
\mathrm{D} 1,100 \mathrm{mg} \text { at } \mathrm{D} 8,75 \mathrm{mg} / \mathrm{month}\end{array}$} \\
\hline PLAI $100 \mathrm{mg}$ & 306.87 & 1 & $306.87[77]$ & Outpatient: 1265 & \\
\hline PLAI 75 mg & 250.73 & 1 & $250.73[78]$ & Prevention phase: 752 & Prevention phase: 75 mg/month \\
\hline RLAI $37.5 \mathrm{mg} / 2 \mathrm{ml}$ & 130.86 & 1 & $130.86[79]$ & Inpatient $^{\mathrm{c}}: 530$ & \multirow{2}{*}{$\begin{array}{l}\text { Initiation and prevention phase: } \\
37.5 \mathrm{mg} \text { biweekly (equivalent to } \\
75 \mathrm{mg} \text { of PLAI monthly) } \\
\text { Note: 2-week oral supplementation } \\
\text { during the initiation phase }\end{array}$} \\
\hline Oral risperidone $4 \mathrm{mg}$ & 29.77 & 30 & $0.99[80]$ & $\begin{array}{l}\text { Outpatient: } 806 \\
\text { Prevention phase: } 785\end{array}$ & \\
\hline ALAI $400 \mathrm{mg}$ & 268.51 & 1 & $268.51[81]$ & Inpatient $^{\mathrm{c}}: 537$ & \\
\hline Oral aripiprazole & 95.92 & 28 & $3.43[82]$ & $\begin{array}{l}\text { Outpatient: } 853 \\
\text { Prevention phase: } 806\end{array}$ & Oral aripiprazole: $15 \mathrm{mg} /$ day \\
\hline OLAI & 218.42 & 1 & NA & $\begin{array}{l}\text { Inpatient }^{\mathrm{c}}: 874 \\
\text { Outpatient: } 1311 \\
\text { Prevention phase: } 1311\end{array}$ & $\begin{array}{l}\text { Only at the hospital. Hypothesis: } \\
\text { half-day hospitalisation cost }\end{array}$ \\
\hline $\mathrm{OO}$ & 43.78 & 28 & $1.56[83]$ & $\begin{array}{l}\text { Inpatient }^{\mathrm{c}}: 874 \\
\text { Outpatient: } 14 \\
\text { Prevention phase: } 141\end{array}$ & OO: $10 \mathrm{mg}$ per day \\
\hline HLAI & 16.53 & 5 & $3.31[84]$ & $\begin{array}{l}\text { Inpatient }^{\mathrm{c}}: 17 \\
\text { Outpatient: } 50 \\
\text { Prevention phase: } 50\end{array}$ & $5 \mathrm{ml} /$ injection biweekly \\
\hline Clozapine & 16.08 & 28 & $0.57[85]$ & $\begin{array}{l}\text { Outpatient: } 155 \\
\text { Prevention phase: } 155\end{array}$ & Maximum $300 \mathrm{mg}$ per day \\
\hline
\end{tabular}

ALAI aripiprazole long-acting injectable, $H L A I$ haloperidol long-acting injectable, $O L A I$ olanzapine long-acting injectable, $O O$ oral olanzapine, $P L A I$ paliperidone long-acting injectable, RLAI risperidone long-acting injectable

a Public price all taxes

b Cost per 3 months reflecting when the initiation phase started

c The inpatient initiation phase includes a period at the hospital and an outpatient setting period after discharge. The reported price is the price of the outpatient setting period only (i.e. 3 months minus the hospitalisation period), since it is assumed that medication costs at hospital were included in the daily price of hospitalisation (i.e. $€ 436.8$ )

with second-line treatments were computed as the weighted average costs of the four LAIs included in the model ( $25 \%$ of aripiprazole LAI, $25 \%$ of olanzapine LAI, $25 \%$ of paliperidone LAI and $25 \%$ of risperidone LAI). Thus, the costs of antipsychotics for one cycle of second-line treatment was set at $€ 611$ for patients who started at the hospital (i.e. corresponding to the period after the discharge from the hospital), and $€ 1059$ where patients were assumed to start in ambulatory care. The medication costs for one cycle of second-line treatment in the prevention phase was assumed to be equal to $€ 913$.

2.4.7.2 Administration Costs LAI antipsychotic injections were administered by a nurse. The tariff of an injection was $€ 7$ according to the SHI [55].

2.4.7.3 Maintenance Costs of Schizophrenia The maintenance cost of schizophrenia was considered to be $€ 1062$ per year, per patient. This was based on the annual mean cost of outpatient care for a patient with schizophrenia from the SHI perspective [56]. We assumed the maintenance cost was similar for all comparators and reflected stable patients without adverse events. Additional costs were added for adverse events and medicines.

2.4.7.4 Costs of Hospitalisation We assumed the cost of initiation to be based on the daily cost of hospitalisation for patients initiating their antipsychotic treatment in the hospital. The hospitalisation cost in a psychiatric unit was estimated in a report by the Court of Auditors at $€ 450$ per day in 2011 (i.e. $€ 450 \times 99.6 / 102.6$ [i.e. CPI 2014/CPI 2012] $=€ 436.84$ in December 2014) [57]. A lower cost was identified by Raymond et al. [24], with a daily hospitalisation cost at $€ 288.30$ in 2009 (i.e. $€ 288.30 \times 99.6 /$ 103.4 [i.e. CPI 2014/CPI 2009] $=€ 277.70$ in December 2014) and was assessed in an extra scenario [24]. 
Table 6 Three-month costs and resources associated with adverse events (2014)

\begin{tabular}{|c|c|c|c|c|}
\hline Adverse event & Resource items & Units and (costs [58]) ( $€$ per 3 months) & Sources & Global cost $(€)$ \\
\hline \multirow[t]{6}{*}{ Extrapyramidal symptoms } & Medicines & Trihexyphenidyl: 180 (16.02) & SmPC [86-88] & 79.80 \\
\hline & & Tropatepine: 225 (29.33) & & \\
\hline & & Biperiden: 135 (14.04) & & \\
\hline & Visits & GP: $1(23.00)$ & Expert opinion & \\
\hline & & Psychiatrist: 1 (37.00) & & \\
\hline & Tests & NI $(0)$ & Expert opinion & \\
\hline \multirow[t]{5}{*}{ Tardive dyskinesia } & Medicines & NI $(0)$ & Expert opinion & 97.00 \\
\hline & Visits & GP: $1(23.00)$ & Expert opinion & \\
\hline & & Psychiatrist: 1 (37.00) & & \\
\hline & & Neurologist: 1 (37.00) & & \\
\hline & Tests & NI $(0)$ & - & \\
\hline Diabetes & Global & $(1318.05)$ & Entred study [89] & 1318.05 \\
\hline \multirow[t]{7}{*}{ Weight gain } & Medicines & NI $(0)$ & - & 114.64 \\
\hline & Visits & GP: $1(23.00)$ & Expert opinion and HAS [90] & \\
\hline & & Psychiatrist: 1 (37.00) & & \\
\hline & & Nutritionist: 1 (23.00) & & \\
\hline & & Endocrinologist: 1 (23.00) & & \\
\hline & Tests & Blood glucose analyses: 1 (1.4) & HAS [90] & \\
\hline & & Lipid abnormality investigations: 1 (7.3) & HAS [90] & \\
\hline
\end{tabular}

$G P$ general practitioner, $N I$ not included

2.4.7.5 Cost in Outpatient Setting In the initiation phase or in case of relapse without hospitalisation, additional costs were associated with the maintenance cost due to the increase in psychiatrist visits. Based on expert opinion, it was assumed that the number of visits for a patient in relapse was multiplied by three compared with a stable patient, leading to an additional cost of $€ 222$ for 3 months [55].

\subsubsection{Costs of Managing Adverse Events Additional} costs due to adverse events considered three main items: medicines, visits and biologic tests. Resources associated with adverse events, except diabetes, were based on expert opinion, with tariffs of the SHI applied [58]. A total average annual cost associated with diabetes management was derived from a French study and converted to quarterly costs in the model [59]. Resources and associated costs are summarised in Table 6.

\subsection{Sensitivity Analyses}

We conducted sensitivity analyses to explore the impact of uncertainty associated with the input parameters, as recommended in the French methodological guide for economic evaluations [27]. As this analysis consisted of multiple comparisons, univariate sensitivity analyses cannot be presented using tornado diagrams because the costs and outcomes vary for each strategy. Therefore, we conducted limited scenario analyses, and the effects of uncertainty were further explored through probabilistic sensitivity analyses (PSA). We conducted one-way sensitivity analyses on paliperidone LAI input parameters only (i.e. a variation of $\pm 15 \%$ was applied based on expert opinion; see Appendix Table 10 for details) in order to identify the main drivers of the model. Extra scenarios were run to test the main assumptions of the model (i.e. daily hospitalisation costs, hospitalisation duration, paliperidone LAI dose, utility values in health state 'Relapse without hospitalisation' and incidence of diabetes).

Monte Carlo PSAs were performed over 10,000 iterations. The mean duration of stabilisation at the hospital was drawn from a truncated Normal distribution. Utility inputs and SMR were estimated using a log-Normal distribution, for which parameter inputs were based on the mean and standard deviation. A Beta distribution was applied to proportions, such as the probabilities of treatment discontinuation (i.e. the proportions of interruption, switch and relapse), the proportion of relapse requiring hospitalisation, the proportion of patients treated with the same antipsychotic after a relapse, as well as the proportions of adverse events based on number of events within a defined population. Adverse events based on SmPC and the proportion of patients initiating their first antipsychotic drug in the hospital setting were drawn from a Uniform distribution using minimum and maximum values. To reflect the different treatment options for second-line treatment, the 
medication changes were drawn from a Dirichlet distribution, the parameters of which were derived from expert opinion. The Dirichlet distribution was also applied to reflect the transition probabilities for untreated patients and the proportion of patients in relapse leaving the hospital. To reflect the uncertainty associated with resource use and costs and to follow a conservative approach (i.e. equivalent weight given to each value across the range of the distribution), a triangular distribution of $\pm 50 \%$ (for costs) or \pm 1 unit (for resources) of the base-case value were applied. The mean time in relapse was drawn from a Gamma distribution.

The details of the parameters of the PSA are available in the technical appendix (Appendix Table 11).

\section{Results}

\subsection{Base Case}

Hospitalisation costs represented between 56 and $72 \%$ of the total undiscounted costs over 5 years (Table 7). As reported in Table 8, risperidone LAI and paliperidone LAI generated the highest number of QALYs gained over 5 years as 3.7642 and 3.7634 QALYs, respectively. Paliperidone LAI was associated with the lowest number of relapses after olanzapine LAI (1.4366 vs. 1.4333). With regards to mean costs, oral olanzapine was the least costly treatment strategy over the 5-year time horizon, with a total cost of $€ 50,379$. Paliperidone LAI was associated with an incremental cost of $€ 501$ over 5 years compared with olanzapine oral. Olanzapine LAI was the most costly treatment, with a 5-year total cost of $€ 55,843$.

The cost per QALY gained and the cost per relapse avoided were calculated as incremental cost-effectiveness measures. In order to compare multiple treatment options, the results are reported in Table 8, and the efficiency frontier on the cost-effectiveness plane in terms of QALYs gained and relapse avoided are presented in Figs. 3 and 4, respectively. Strategies are first sorted by descending costs to exclude dominated strategies and strategies subject to extended dominance (i.e. dominated by a linear combination of two existing strategies) before calculating the incremental cost-effectiveness ratios (ICERs) between two consecutive strategies.

With regards to the cost per QALY gained, paliperidone LAI dominated aripiprazole LAI, olanzapine LAI and haloperidol LAI. Paliperidone LAI was associated with an ICER of $€ 2411$ per QALY gained compared with oral olanzapine.

In terms of cost per avoided relapse, paliperidone LAI dominated risperidone LAI, aripiprazole LAI and haloperidol LAI. Paliperidone LAI was associated with an ICER of $€ 1782$ per avoided relapse compared with oral olanzapine.

\subsection{Sensitivity Analyses}

\subsubsection{One-Way Sensitivity Analyses}

The impact of input parameters was tested for paliperidone LAI. Input parameters that had the greatest impact on the cost per QALY gained were the probabilities of switch due to lack of tolerance and rates of adverse events. In terms of cost per relapse avoided, the one-way sensitivity analyses showed that probabilities of treatment interruption and probabilities of relapse due to lack of efficacy as parameters had the highest impact on the ICER.

\subsubsection{Extra Scenarios}

In the extra scenario associated with using the cost of hospitalisation from Raymond et al. [24] (i.e. $€ 277.70$ in December 2014), paliperidone LAI remained the least

Table 7 Breakdown costs by health state and total costs, over 5 years $(€)$

\begin{tabular}{lllllllll}
\hline & Stable initiation & Stable prevention & $\begin{array}{l}\text { Stable non- } \\
\text { treated }\end{array}$ & $\begin{array}{l}\text { Relapse } \\
\text { hospitalisation }\end{array}$ & $\begin{array}{l}\text { Relapse non- } \\
\text { hospitalisation }\end{array}$ & AEs & $\begin{array}{l}\text { Total costs } \\
\text { undiscounted }\end{array}$ \\
\hline OO & 1248 & 10,848 & 228 & 39,450 & 707 & 2630 & 55,113 & 50,379 \\
discounted $^{\text {a }}$
\end{tabular}

$A E$ adverse event, $A L A I$ aripiprazole long-acting injectable, $H L A I$ haloperidol long-acting injectable, $O L A I$ olanzapine long-acting injectable, $O O$ oral olanzapine, $P L A I$ paliperidone long-acting injectable, $R L A I$ risperidone long-acting injectable

${ }^{a}$ Discounted at $4 \%$ 
Table 8 Results of the base case; ICER ( $€$ per QALY gained and relapse avoided) per patient and per treatment over 5 years

\begin{tabular}{llllll}
\hline & Discounted costs $^{\mathrm{a}}(€)$ & Discounted QALYs $^{\mathrm{a}}$ & Discounted relapses $^{\mathrm{a}}$ & ICER/QALY gained & ICER/relapse avoided \\
\hline OO & 50,379 & 3.5558 & 1.7175 & & $€ 1782$ \\
PLAI & 50,880 & 3.7634 & 1.4366 & $€ 2411$ & Dominated \\
RLAI & 54,952 & 3.7642 & 1.4387 & $€ 4,770,018$ & Dominated \\
HLAI & 55,127 & 3.6227 & 1.8046 & Dominated & Dominated \\
ALAI & 55,657 & 3.7549 & 1.4648 & Dominated & $€ 1,529,377$ \\
OLAI & 55,843 & 3.5753 & 1.4333 & \\
\hline
\end{tabular}

Strategies were sorted by descending costs to exclude dominated strategies (i.e. more costly and less effective) and extendedly dominated strategies. The ICERs were then computed between two consecutive strategies, which have not been excluded

$A L A I$ aripiprazole long-acting injectable, $H L A I$ haloperidol long-acting injectable, ICER incremental cost-effectiveness ratio, $O L A I$ olanzapine long-acting injectable, $O O$ oral olanzapine, $P L A I$ paliperidone long-acting injectable, $Q A L Y$ quality-adjusted life-year, $R L A I$ risperidone longacting injectable

${ }^{a}$ Discounted at $4 \%$

Fig. 3 Efficiency frontier in terms of quality-adjusted lifeyears gained. ALAI aripiprazole long-acting injectable, $H L A I$ haloperidol long-acting injectable, OLAI olanzapine long-acting injectable, $O O$ oral olanzapine, PLAI paliperidone long-acting injectable, $Q A L Y s$ quality-adjusted life-years, $R L A I$ risperidone long-acting injectable

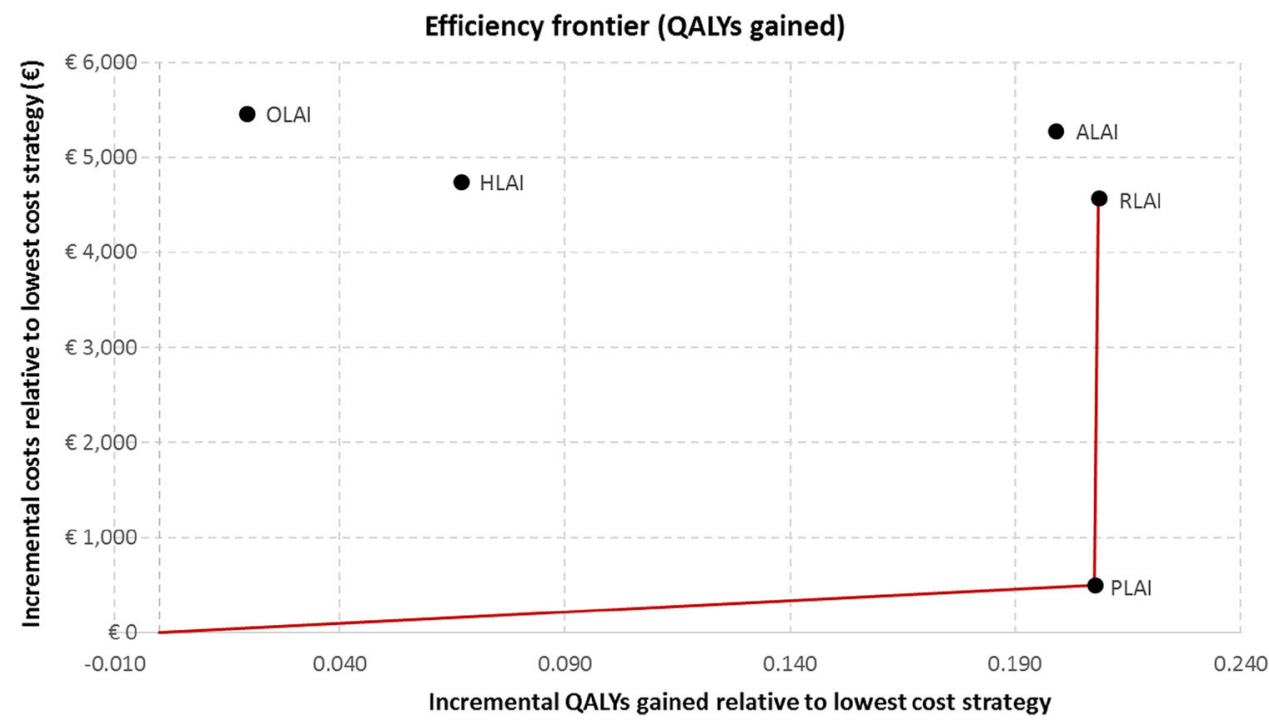

conclusion (i.e. ICER of paliperidone LAI vs. olanzapine oral of $€ 2368$ per QALY instead of $€ 2411$ per QALY in the base case, and ICER of risperidone LAI vs. oral olanzapine of $€ 4,936,304$ per QALYs instead $€ 4,770,018$ per QALY in the base case).

Finally, in the scenario in which the diabetes incidence rates for all comparators were set up to the paliperidone LAI rate (i.e. $0.55 \%$ ), aripiprazole LAI was associated with a slightly higher number of QALYs compared with paliperidone LAI (i.e. +0.003 QALYs gained for aripiprazole LAI vs. paliperidone LAI) and with an ICER of $€ 1,5136,483$ versus paliperidone LAI. The other conclusions were similar to those for the base-case analysis.

\subsubsection{Probabilistic Sensitivity Analysis}

We conducted PSAs with 10,000 iterations. The incremental costs and effects of paliperidone LAI versus all other comparators (i.e. risperidone LAI, aripiprazole LAI, 
Fig. 4 Efficiency frontier in terms of relapse avoided. ALAI aripiprazole long-acting injectable, HLAI haloperidol long-acting injectable, $O L A I$ olanzapine long-acting injectable, $O O$ oral olanzapine, PLAI paliperidone long-acting injectable, $R L A I$ risperidone long-acting injectable

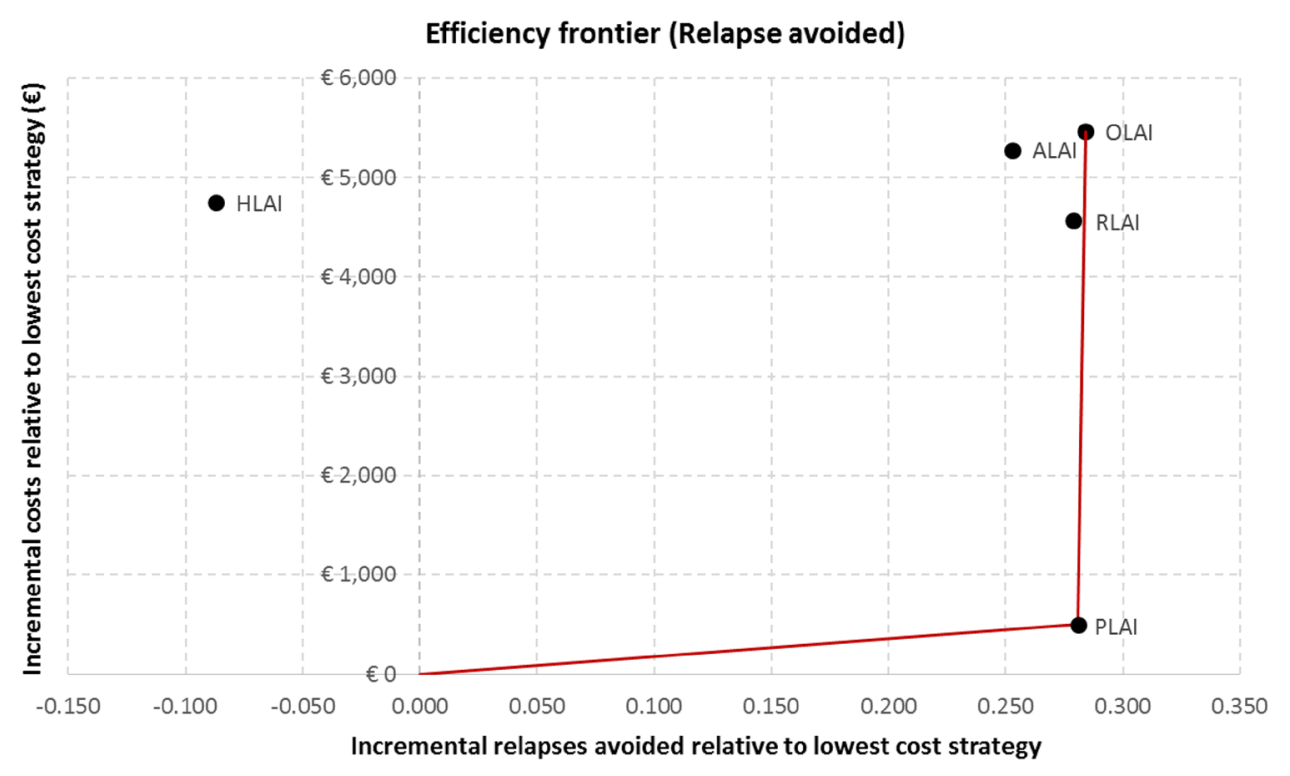

olanzapine LAI, haloperidol and oral olanzapine) for each simulation were reported on a cost-effectiveness plane (Fig. 5). The multiple comparison analyses on the costeffectiveness plane enabled a simultaneous assessment of all the treatment options. However, the presentation of the cost-effectiveness results is more complex than in pairwise comparisons [60]. The optimal strategy is identified as the strategy associated with the highest net monetary benefit $(\mathrm{NMB})^{7}$ below the maximum willingness to pay (WTP) for an extra QALY gained (or relapse avoided). Overall, paliperidone LAI generated more QALYs and was less costly than other comparators. When making pairwise comparisons, paliperidone LAI was dominant in terms of QALYs gained (i.e. more effective and less costly) in more than $64 \%$ of the 10,000 simulations for each comparator, except versus risperidone LAI $(41.76 \%)$. As stated in a recent report from the HAS, France has no official threshold of a maximum WTP for an additional QALY [61]. An estimated range based on published data was provided as example (i.e. between $€ 1811$ and $€ 54,612$ ). Other examples can be identified in the literature, for instance, Deconinck et al. used a threshold of $€ 50,000$ per QALY in a French study in oncology [62]. Thus, to follow a conservative approach, results are presented here using thresholds lower than $€ 30,000$.

Above a threshold of $€ 8000$ per QALY gained, the acceptability curve showed that paliperidone LAI had a probability $>50 \%$ to be identified as the optimal strategy in comparison with all other strategies simultaneously in terms of QALYs gained (Fig. 6).

In terms of cost per relapse avoided, the cost-effectiveness plane showed a linear relationship between

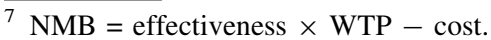

paliperidone LAI and each comparator, which could be explained by the high correlation between relapse and hospitalisation (Fig. 7). Head-to-head comparisons showed that paliperidone LAI was strongly dominant in more than $50 \%$ of the simulations when compared with each comparator except olanzapine LAI (i.e. the probability for paliperidone LAI of dominating olanzapine LAI was $47.30 \%$ ). At a threshold lower than $€ 30,000$, the acceptability curve showed that paliperidone LAI was likely to be cost effective in more than $40 \%$ of the simulations compared with all other strategies simultaneously (Fig. 8).

\section{Discussion}

Schizophrenia is a disabling mental disorder characterised by remission phases and relapse episodes. These relapse episodes can often lead to hospitalisation and have a significant impact on the burden of disease [45]. LAI administration tends to improve patient compliance and is therefore recommended in the prevention of relapses [12].

The present study, to the best of our knowledge, is the first model to use real-life French hospitalisation data to estimate the efficacy of antipsychotics [26] with the singularity to distinguish initiation and prevention phases.

Several health economic models in schizophrenia have been developed [28, 29, 63, 64], but only one study assessing the cost effectiveness of different antipsychotics in France has been identified [30]. In 2005, Llorca et al. [25] evaluated the impact in terms of medical benefits and costs of risperidone LAI, haloperidol LAI or oral olanzapine over a 2-year time horizon. To consider the advantages of LAIs (e.g. better compliance), several hypotheses 
Fig. 5 Cost-effectiveness plane in terms of cost per qualityadjusted life-year gained (paliperidone long-acting injectable vs. comparators). $A L A I$ aripiprazole long-acting injectable, HLAI haloperidol long-acting injectable, OLAI olanzapine long-acting injectable, $O O$ oral olanzapine, PLAI paliperidone long-acting injectable, $Q A L Y s$ qualityadjusted life-years, $R L A I$ risperidone long-acting injectable

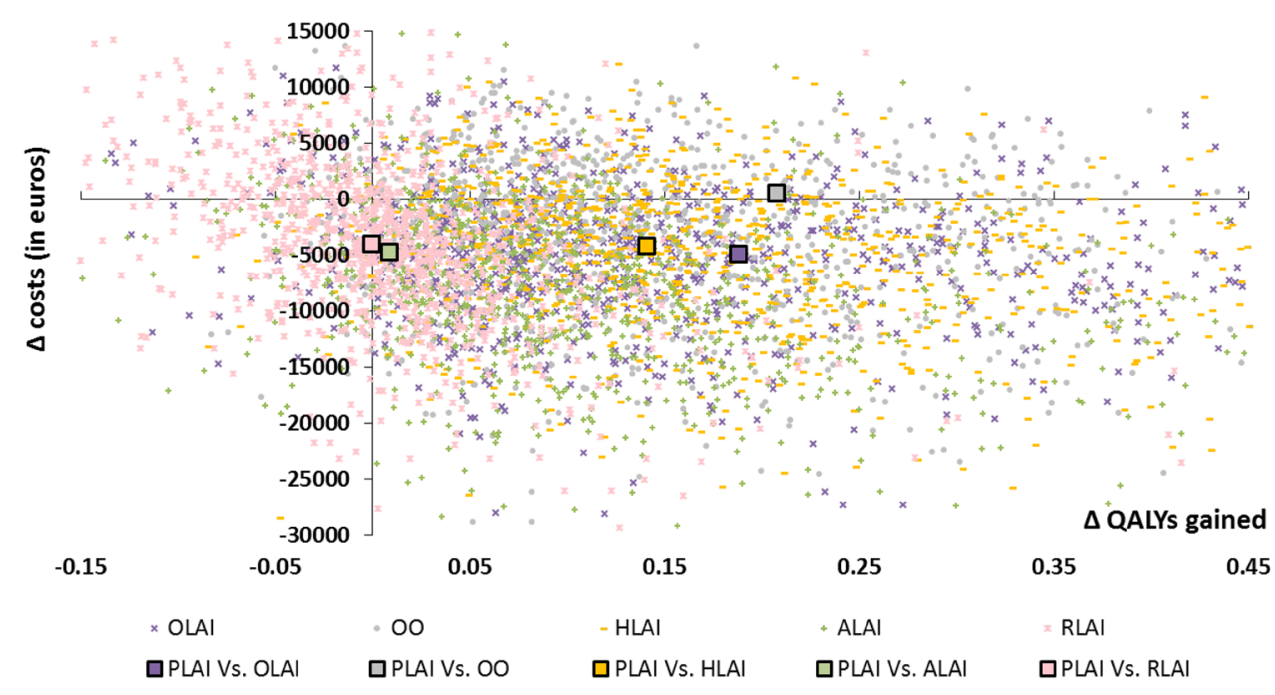

Fig. 6 Cost-effectiveness acceptability curve in terms of cost per quality-adjusted lifeyear gained. ALAI aripiprazole long-acting injectable, $H L A I$ haloperidol long-acting injectable, $O L A I$ olanzapine long-acting injectable, $O O$ oral olanzapine, $P L A I$ paliperidone long-acting injectable, $Q A L Y S$ quality-adjusted life-years, $R L A I$ risperidone long-acting injectable

Fig. 7 Cost-effectiveness plane in terms of cost per relapse avoided (paliperidone longacting injectable vs. comparators). ALAI aripiprazole long-acting injectable, $H L A I$ haloperidol long-acting injectable, $O L A I$ olanzapine long-acting injectable, $O O$ oral olanzapine, PLAI paliperidone long-acting injectable, $R L A I$ risperidone long-acting injectable
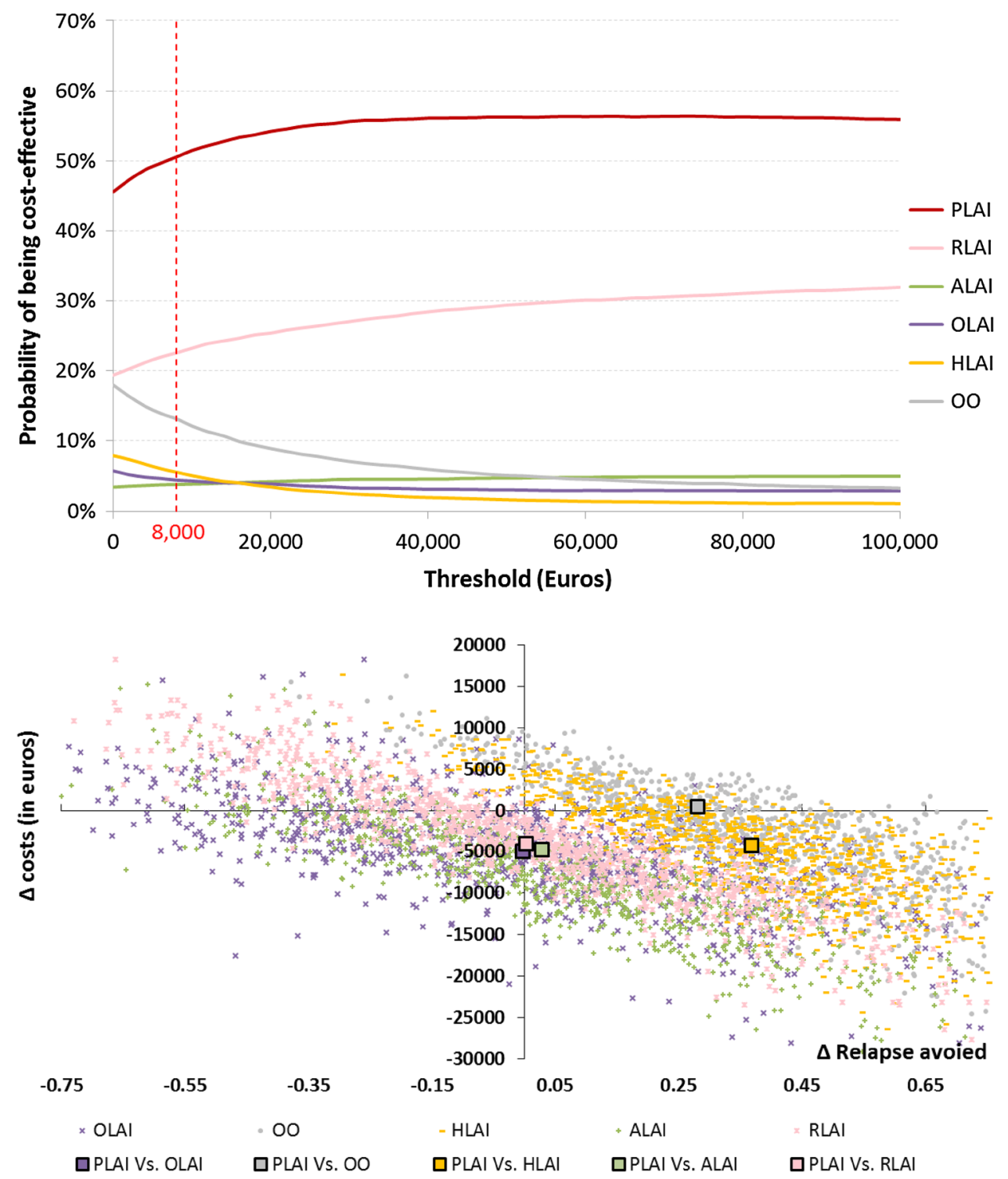
Fig. 8 Cost-effectiveness acceptability curve in terms of cost per relapse avoided. ALAI aripiprazole long-acting injectable, HLAI haloperidol long-acting injectable, $O L A I$ olanzapine long-acting injectable, $O O$ oral olanzapine, PLAI paliperidone long-acting injectable, $R L A I$ risperidone long-acting injectable

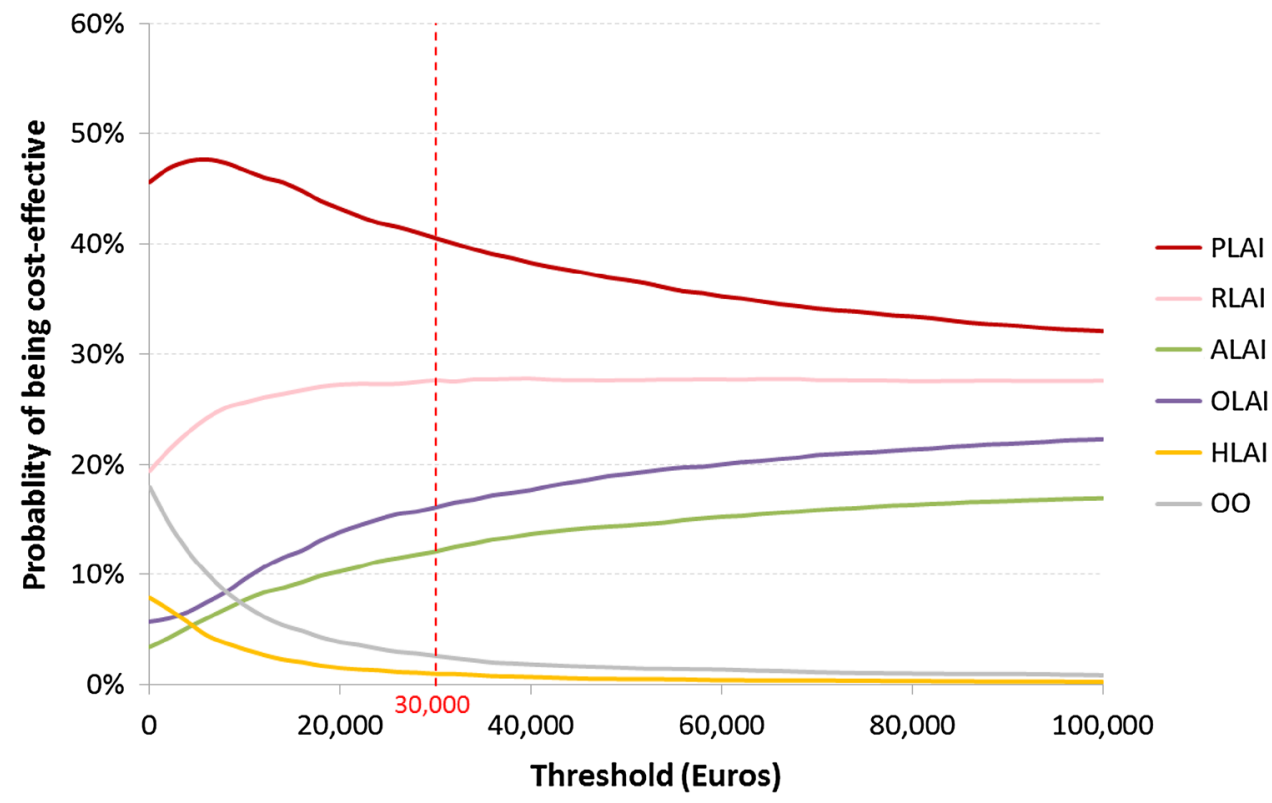

were made, including the success rate (i.e. patient on the same antipsychotic treatment over 2 years) was increased by $5 \%$ for first-generation LAI antipsychotics and by $10 \%$ for second-generation LAI antipsychotics compared with an oral equivalent, while the efficacy of oral olanzapine was unchanged. The study showed that risperidone LAI was associated with the greatest proportion of responders and the lowest cost $(82.70 \%$; $€ 14,055)$, followed by oral olanzapine $(75.80 \%$; €14,351) and haloperidol LAI $(57.30 \%$; €17,203). In comparison, our model concluded that oral olanzapine was the least costly strategy (€21,124; year 2014 undiscounted costs), followed by haloperidol LAI $(€ 26,184)$ and risperidone LAI $(€ 26,687)$ at a 2-year time horizon. However, at a 5-year time horizon, our model concluded that risperidone LAI becomes less costly than haloperidol LAI. If we assume that relapses avoided represent treatment success, our results are consistent with those found by Llorca et al. [25] (i.e. risperidone LAI was associated with the lowest number of relapses, followed by oral olanzapine and haloperidol LAI, at a 2-year time horizon).

Our model estimated an average annual cost of approximatively $€ 11,500$ associated with the healthcare management of a patient with schizophrenia, compared with average costs of $€ 7500$ in the publication from 2005 . $^{8}$ The cost difference can be explained first by the inclusion of three additional adverse effects (i.e. TD, diabetes and WG) and second by the distinction between the two phases

\footnotetext{
8 The unweighted average cost after 1 year of long-acting risperidone, oral olanzapine and haloperidol decanoate are provided here for information only, and thus must be interpreted with caution.
}

in our model, which allowed a better estimate of the costs associated with the initiation of a treatment. For comparison, in 2014 the French Ministry of Health estimated the average cost of therapeutic management of schizophrenia in France to be approximately $€ 15,000$ [7].

Six analyses assessing the cost effectiveness of paliperidone LAI have been identified in other countries: Mehnert et al. [28] in Sweden, Zeidler et al. [29] in Germany, Kolek et al. [64] in the Czech Republic, Einarson et al. [63] in Finland, Citrome et al. [65] in the USA and Lee et al. in Wales [23].

The first three models were based on the same Markov model structure (i.e. Mehnert et al. [28]). The Swedish analysis showed that paliperidone LAI dominated risperidone LAI and olanzapine LAI over a 5-year time horizon [28]. In the German study, paliperidone LAI dominated risperidone LAI. However, paliperidone LAI was associated with an ICER of $€ 748 / Q A L Y$ gained and $€ 278 /$ avoided relapse compared with olanzapine LAI [29]. The model in the study from the Czech Republic showed that paliperidone LAI was cost effective from the payer's perspective and was associated with an ICER of $€ 16,233 /$ QALY gained when compared with oral risperidone [64]. Results of our analysis differed from those of the Swedish and the German models, partly due to input parameters and the health organisation system. In the present model, efficacy data were based on real-life hospitalisation rates whilst efficacy inputs were weighted by compliance ratios in the other studies. Moreover, mean hospitalisation duration varied across studies, with 66.4 days in Mehnert et al. [28] and 33.7 days in Zeidler et al. [29], when they were time dependent based on real data in our analysis (i.e. 
assuming $85 \%$ of patients in relapse leaving hospital within 3 months, $10 \%$ at 3-6 months, $2 \%$ at 6-9 months, $1 \%$ at 9-12 months and $2 \%$ after 12 months; see Appendix Table 11).

The Finnish study assessed paliperidone LAI, risperidone LAI and olanzapine LAI in patients switched to LAI antipsychotics due to compliance issues with previous treatments [63]. At the 1-year time horizon, paliperidone LAI was associated with better outcomes and was less costly than risperidone LAI and olanzapine LAI. However, the heterogeneity of input parameter sources may be considered a limitation, i.e. risperidone LAI data were based on an observational study conducted in Spain [66], while olanzapine LAI inputs were derived from a real-life study performed in the USA [67] and an international clinical trial [68].

Finally, the Welsh analysis compared the cost effectiveness of paliperidone LAI versus risperidone LAI, and the authors concluded that paliperidone LAI dominated risperidone LAI in terms of QALYS gained [23]. The relative incremental discounted costs and incremental discounted QALYs after 10 years between the two treatments was $-2.90 \%$ (paliperidone LAI less costly than risperidone $\mathrm{LAI}$ ) and $2.83 \%$ (paliperidone LAI associated with more QALYs than risperidone LAI), respectively. In our model, after 5 years, the relative incremental discounted costs and QALYs of paliperidone LAI versus risperidone LAI were -7.41 and $0.02 \%$, respectively. It could be noted that the Welsh model assumed a higher utility for paliperidone LAI than for risperidone LAI in the remission state in order to take into consideration the lower frequency of injections associated with paliperidone LAI (i.e. utility decrement associated with pain at the injection site). Based on French expert opinion, we decided there was not enough clinical evidence to use such a disutility in the French context.

A recent cost-effectiveness analysis was conducted in the USA to assess the efficiency of aripiprazole LAI versus paliperidone LAI in various dosing scenarios [65]. Overall, results were in favour of aripiprazole LAI, as it was associated with fewer relapses at lower costs or a reasonable cost-effectiveness threshold compared with paliperidone LAI at the 1-year time horizon. Nevertheless, efficacy and safety parameters were derived from product prescribing information and pivotal trials, which could introduce biases in the results caused by targeted population heterogeneity and lack of adjustment of the treatment on the placebo arms.

A systematic literature review of cost-effectiveness analyses in LAI antipsychotics was conducted by Achilla and McCrone in 2013 [69]. Of the 154 records screened, 28 studies were included in the review. Heterogeneity in terms of outcomes such as data sources used for costs and resources and study durations made the comparison between countries and studies difficult. However, with the exclusion of studies that were not directly comparable, the authors concluded that paliperidone extendedrelease was the most cost-effective option compared with other oral second-generation or first-generation LAI antipsychotics. It was also reported that generally, longacting second-generation antipsychotics (especially risperidone) were cost effective versus long-acting haloperidol and other oral or depot formulations as firstline treatments.

Given the heterogeneity between studies, our results in terms of costs, relapses and QALYs were generally in line with previous analyses and were validated by experts.

\subsection{Limitations}

Our study was subject to some limitations due to the assumptions applied to the model when data were not available. Beyond missing data, the main limitations to highlight are the heterogeneity of clinical practice in schizophrenia and the hospitalisation cost with no clear accepted reference in France.

Due to a lack of data, the model does not enable assessment of treatment effects at an individual level (e.g. level of compliance according to age, year since diagnosis, patient history, etc.). However, a cohort approach seems to be a reasonable choice to accurately assess the global incremental impacts between antipsychotics, with the reserve of potential bias due to the heterogeneity of patient's characteristics in real life.

In our model, we assumed that patients were treated with antipsychotic monotherapy in order to focus on the effect of studied antipsychotics. In reality, $30 \%$ of patients with schizophrenia are managed with antipsychotic combination therapy [70]. Compliance with treatment is difficult to capture and quantify; moreover, data in France were scarce, so hospitalisation rates were used to derive the risk of relapse based on CGS [26]. However, it has been shown that hospitalisation is the best proxy for relapses for patients with schizophrenia, and real-life data ensure robustness to parameter values used in the model [26, 45].

Although doses were derived from SmPCs, they may not always reflect doctor's prescriptions, and the average monthly dose for paliperidone LAI may be higher in real life. However, paliperidone LAI monthly dose was increased to $100 \mathrm{mg}$ in the sensitivity scenario, and paliperidone LAI remained the less costly LAI. 
Data focusing on France to populate the model were limited, especially for recently approved drugs (such as aripiprazole LAI, approved in 2013 [71]) leading to the need for several assumptions. In this context, proportions of adverse events were partly based on ranges provided in SmPCs. Mid-points between the highest and the lowest interval limits were applied. Proportions of adverse events were consistent with clinical practice, although the proportion of diabetes associated with aripiprazole LAI was discussed (i.e. $1 \%$ per cycle in our model, based on a conservative approach using the lower bound of the range from $1 / 100$ to $1 / 10$ [34]). However, it was considered the most reliable source based on expert opinion and was tested in sensitivity analysis. Another limitation due to lack of data was that the model assumed similar and constant probabilities of treatment discontinuation regardless of treatment line and time. In clinical practice, patients with prior relapse have a greater probability of relapse than stable patients without relapse, while patients stable after 1 year of treatment have a reduced probability of relapse or switch due to lack of tolerance. Thus, and according to clinical experts ${ }^{1}$, our analysis may underestimate the proportion of patients continuing to receive initial treatment over time compared with real life. However, the evolution of this proportion was consistent with previous analyses when considering similar time-independent transition assumptions [23, 28]. Probabilities of leaving the hospital during a relapse episode were derived from real-life data from one hospital centre and may not be representative of all centres in France. It was assumed that EPS events lasted for one cycle of 3 months. Patients faced the same probability of experiencing an EPS event at each cycle regardless of his/her previous EPS event sequence (due to memoryless Markov property), and thus EPS events may have been overestimated. The maintenance cost of schizophrenia was based on an aggregated cost from the SHI database. This cost was applied to stable patients without adverse events, and additional costs have been associated with adverse events. Thus, maintenance cost may also be overestimated.

Finally, it should be noted that, although validation of the model by external reviewers would have strengthened the study methods, limited time and resources precluded this. However, extensive PSAs were performed. These analyses aimed to assess the impact of uncertain input parameters and assumptions (mentioned above) on model results. PSA showed that results in terms of QALYs were robust, with paliperidone LAI as optimal strategy in more than $50 \%$ of cases for a threshold of WTP above $€ 8000$ per QALY gained.

\section{Conclusions}

The present analysis highlighted that paliperidone LAI is a relevant option in the treatment of patients with schizophrenia. Using an original model based on original observational data provides additional information to support decision choice in the management of schizophrenia in France. This study also highlighted the scarcity of available data, especially on long-term efficacy. Observational studies should be conducted in order to validate theoretical results presented in this study.

\section{Compliance with Ethical Standards}

Funding The study was funded by Janssen-Cilag.

Conflict of interest S. Druais is employed by Amaris, which received funding for this project from Janssen-Cilag. A. Doutriaux is employed by Amaris, which received funding for this project from Janssen-Cilag. M. Cognet was employed by Amaris, which received funding for this project from Janssen-Cilag. A. Godet is employed by Janssen-Cilag. P. Guillon is employed by Janssen-Cilag. Professor C. Lançon has received grants, honoraria or consulting fees from Janssen-Cilag, Lundbeck and Roche. P. Levy has received grants, honoraria or consulting fees from Abbott, AbbVie, Actelion, Amgen, Astellas, Anergis, Bayer, Becton Dickinson, Biogen, BMS, Conceptus, Daïchi-Sankyo, Eli Lilly, EOS, Gilead, GSK, Hospira, Impeto Médical, Janssen, MSD, Mundipharma, Novartis, Novo Nordisk, Roche, Stallergènes and Sanofi Pasteur MSD. Dr L. Samalin has received grants, honoraria or consulting fees from AstraZeneca, Bristol-Myers Squibb, Janssen-Cilag, Lundbeck, Otsuka, SanofiAventis and Takeda.

Open Access This article is distributed under the terms of the Creative Commons Attribution-NonCommercial 4.0 International License (http://creativecommons.org/licenses/by-nc/4.0/), which permits any noncommercial use, distribution, and reproduction in any medium, provided you give appropriate credit to the original author(s) and the source, provide a link to the Creative Commons license, and indicate if changes were made. 


\section{Technical Appendix}

See Tables 9, 10, 11 and 12 .

Table 9 HAS guidelines for French economic evaluation studies [26]

\begin{tabular}{|c|c|c|}
\hline & Reference case analysis & Status \\
\hline \multirow[t]{2}{*}{ The method of evaluation } & $\begin{array}{l}\text { CUA or CEA according to the nature of the health effects } \\
\text { of the intervention }\end{array}$ & Required reference \\
\hline & $\begin{array}{l}\text { If HR-QOL is an important consequence, a CUA is used } \\
\text { If health-related HR-QOL is not an important } \\
\text { consequence, a CEA is used }\end{array}$ & Required reference \\
\hline Perspective & Collective perspective & Required reference \\
\hline On costs & All healthcare funders & \\
\hline On health effects & $\begin{array}{l}\text { Population whose health is affected (identification and } \\
\text { measurement of health effects) and general public } \\
\text { (preference-based scores) }\end{array}$ & \\
\hline Population analysed & All the individuals concerned, directly or indirectly & Preferred reference \\
\hline Intervention comparators & $\begin{array}{l}\text { All interventions competing with the intervention studied } \\
\text { are identified } \\
\text { The choice of interventions included as comparator is the } \\
\text { responsibility of the author, and is justified }\end{array}$ & Required reference \\
\hline Time horizon & $\begin{array}{l}\text { A time horizon long enough to reflect all expected } \\
\text { differences in costs and health effects }\end{array}$ & Required reference \\
\hline Discount rate & $\begin{array}{l}\text { Discounting is done at the public discount rate. It stood at } \\
4 \% \text { at the time of writing this guide and views the } \\
\text { relative price of the health effects to the community as } \\
\text { being invariable over time } \\
\text { After } 30 \text { years, the discount rate linearly declines to } 2 \%\end{array}$ & Required reference \\
\hline \multirow[t]{3}{*}{ Summary of data } & $\begin{array}{l}\text { Based on a systematic and critical review of clinical and } \\
\text { economic studies }\end{array}$ & Required reference \\
\hline & $\begin{array}{l}\text { Based on data from all relevant studies, subject to their } \\
\text { ability to limit bias and to consider 'real-life' practice }\end{array}$ & Required reference \\
\hline & French data & Preferred reference \\
\hline \multirow[t]{2}{*}{ Heath outcome criteria } & QALYs in CUAs & Required reference \\
\hline & Life-years in CEAs & Preferred reference \\
\hline Costs criteria & Production costs & Required reference \\
\hline \multirow[t]{2}{*}{$\begin{array}{l}\text { Conclusions of health } \\
\text { economic evaluation }\end{array}$} & $\begin{array}{l}\text { Efficiency frontier and calculation of an ICER for non- } \\
\text { dominated interventions }\end{array}$ & Required reference \\
\hline & $\begin{array}{l}\text { Analysis of transfers of spending between healthcare } \\
\text { funders }\end{array}$ & Preferred reference \\
\hline \multirow{2}{*}{$\begin{array}{l}\text { Critical analysis of } \\
\text { the evaluation }\end{array}$} & Analysis of variability and uncertainty, whatever the source & Required reference \\
\hline & $\begin{array}{l}\text { Discussion of the conclusions and limitations of the } \\
\text { evaluation }\end{array}$ & Required reference \\
\hline
\end{tabular}

Reference case analysis defines the features of health economic evaluation at HAS and the recommended methodology for each component of an analysis. It distinguishes between "required" references, to which the author must strictly comply, and "preferred" references, which allow the use of a different method when this is clearly justified

$C U A$ cost-utility analysis, $C E A$ cost-effectiveness analysis, $H R$ - $Q O L$ health-related quality of life, ICER incremental cost-effectiveness ratio, $Q A L Y$ quality-adjusted life-year 
Table 10 One-way sensitivity analysis: input parameters

\begin{tabular}{lll}
\hline Items & Minimum ${ }^{\mathrm{a}}(\%)$ & Maximum $^{\mathrm{a}}(\%)$ \\
\hline Discount rate & -15 & +15 \\
Age at baseline & -15 & +15 \\
Proportion of male & -15 & +15 \\
SMR & -15 & +15 \\
Probability of interruption (due to patient choice, lost to follow up and other reasons) & -15 & +15 \\
Probability of relapse (due to lack of efficacy) & -15 & +15 \\
Probability of switch (due to lack of tolerance) & -15 & +15 \\
Adverse events & 90.0 & 100.0 \\
Initiation of a new antipsychotic (except clozapine) without relapse - outpatient & 0.0 \\
Initiation of a new antipsychotics without relapse - outpatient & -15 \\
Hospitalisation cost & -15 & 20.0 \\
Maintenance cost & -15 & +15 \\
Utility scores (health states) & -15 \\
Utility decrement (adverse events) & +15 \\
\hline
\end{tabular}

SMR standardised mortality rate

${ }^{a}$ Minimums and maximums based on expert opinions

Table 11 Probabilistic sensitivity analysis: input parameters and distributions

\begin{tabular}{|c|c|c|c|c|c|c|}
\hline \multirow{2}{*}{$\frac{\text { Input parameters }}{\text { Mortality data }}$} & \multirow[t]{2}{*}{ Distribution } & \multicolumn{4}{|c|}{ PSA parameters } & \multirow[t]{2}{*}{ Comments } \\
\hline & & Median & ET & $\mu$ & $\sigma$ & \\
\hline SMR (median): stable: male & Log-normal & 3.02 & 0.15 & 1.1 & 0.1 & Hypothesis: $\mathrm{SD}=10 \% \times$ mean \\
\hline SMR (median): stable: female & Log-normal & 2.37 & 0.12 & 0.9 & 0.1 & Hypothesis: SD $=10 \% \times$ mean \\
\hline SMR median: relapse & Log-normal & 6.20 & 0.32 & 1.8 & 0.1 & Hypothesis: SD $=10 \% \times$ mean \\
\hline \multicolumn{7}{|l|}{ Treatment sequences } \\
\hline \multicolumn{2}{|c|}{ First line: $\%$ of pts initiating AP1 at the hospital } & Min & Max & $a$ & $b$ & \\
\hline PLAI & Uniform & $80 \%$ & $100 \%$ & 0.8 & 1.0 & \\
\hline RLAI & Uniform & $80 \%$ & $100 \%$ & 0.8 & 1.0 & \\
\hline ALAI & Uniform & $80 \%$ & $100 \%$ & 0.8 & 1.0 & \\
\hline OLAI & Uniform & $80 \%$ & $100 \%$ & 0.8 & 1.0 & \\
\hline HLAI & Uniform & $80 \%$ & $100 \%$ & 0.8 & 1.0 & \\
\hline $\mathrm{OO}$ & Uniform & $00 \%$ & $20 \%$ & 0.0 & 0.2 & \\
\hline Second line & & Mean & Var & $\alpha j$ & $\beta=1$ & \\
\hline \multicolumn{7}{|l|}{ After PLAI } \\
\hline PLAI & Dirichlet & $25 \%$ & $0.25 \%$ & 25.0 & 1.0 & Hypothesis: Var $=$ mean $/ 100$ \\
\hline RLAI & Dirichlet & $25 \%$ & $0.25 \%$ & 25.0 & 1.0 & Hypothesis: Var $=$ mean $/ 100$ \\
\hline ALAI & Dirichlet & $25 \%$ & $0.25 \%$ & 25.0 & 1.0 & Hypothesis: Var $=$ mean $/ 100$ \\
\hline OLAI & Dirichlet & $25 \%$ & $0.25 \%$ & 25.0 & 1.0 & Hypothesis: Var $=$ mean $/ 100$ \\
\hline \multicolumn{7}{|l|}{ After RLAI } \\
\hline PLAI & Dirichlet & $25 \%$ & $0.25 \%$ & 25.0 & 1.0 & Hypothesis: Var $=$ mean $/ 100$ \\
\hline RLAI & Dirichlet & $25 \%$ & $0.25 \%$ & 25.0 & 1.0 & Hypothesis: Var $=$ mean $/ 100$ \\
\hline ALAI & Dirichlet & $25 \%$ & $0.25 \%$ & 25.0 & 1.0 & Hypothesis: Var $=$ mean $/ 100$ \\
\hline OLAI & Dirichlet & $25 \%$ & $0.25 \%$ & 25.0 & 1.0 & Hypothesis: Var $=$ mean $/ 100$ \\
\hline \multicolumn{7}{|l|}{ After ALAI } \\
\hline PLAI & Dirichlet & $25 \%$ & $0.25 \%$ & 25.0 & 1.0 & Hypothesis: Var $=$ mean $/ 100$ \\
\hline RLAI & Dirichlet & $25 \%$ & $0.25 \%$ & 25.0 & 1.0 & Hypothesis: Var $=$ mean $/ 100$ \\
\hline ALAI & Dirichlet & $25 \%$ & $0.25 \%$ & 25.0 & 1.0 & Hypothesis: Var $=$ mean $/ 100$ \\
\hline OLAI & Dirichlet & $25 \%$ & $0.25 \%$ & 25.0 & 1.0 & Hypothesis: Var $=$ mean $/ 100$ \\
\hline
\end{tabular}


Table 11 continued

\begin{tabular}{|c|c|c|c|c|c|c|}
\hline Input parameters & Distribution & \multicolumn{4}{|c|}{ PSA parameters } & Comments \\
\hline \multicolumn{7}{|l|}{ After OLAI } \\
\hline PLAI & Dirichlet & $25 \%$ & $0.25 \%$ & 25.0 & 1.0 & Hypothesis: Var $=$ mean $/ 100$ \\
\hline RLAI & Dirichlet & $25 \%$ & $0.25 \%$ & 25.0 & 1.0 & Hypothesis: Var $=$ mean $/ 100$ \\
\hline ALAI & Dirichlet & $25 \%$ & $0.25 \%$ & 25.0 & 1.0 & Hypothesis: Var $=$ mean $/ 100$ \\
\hline OLAI & Dirichlet & $25 \%$ & $0.25 \%$ & 25.0 & 1.0 & Hypothesis: Var $=$ mean $/ 100$ \\
\hline \multicolumn{7}{|l|}{ After HLAI } \\
\hline PLAI & Dirichlet & $25 \%$ & $0.25 \%$ & 25.0 & 1.0 & Hypothesis: Var $=$ mean $/ 100$ \\
\hline RLAI & Dirichlet & $25 \%$ & $0.25 \%$ & 25.0 & 1.0 & Hypothesis: Var $=$ mean $/ 100$ \\
\hline ALAI & Dirichlet & $25 \%$ & $0.25 \%$ & 25.0 & 1.0 & Hypothesis: Var $=$ mean $/ 100$ \\
\hline OLAI & Dirichlet & $25 \%$ & $0.25 \%$ & 25.0 & 1.0 & Hypothesis: Var $=$ mean $/ 100$ \\
\hline \multicolumn{7}{|l|}{ After OO } \\
\hline PLAI & Dirichlet & $25 \%$ & $0.25 \%$ & 25.0 & 1.0 & Hypothesis: Var $=$ mean $/ 100$ \\
\hline RLAI & Dirichlet & $25 \%$ & $0.25 \%$ & 25.0 & 1.0 & Hypothesis: Var $=$ mean $/ 100$ \\
\hline ALAI & Dirichlet & $25 \%$ & $0.25 \%$ & 25.0 & 1.0 & Hypothesis: Var $=$ mean $/ 100$ \\
\hline OLAI & Dirichlet & $25 \%$ & $0.25 \%$ & 25.0 & 1.0 & Hypothesis: Var $=$ mean $/ 100$ \\
\hline \multicolumn{7}{|l|}{ Probabilities of interruption } \\
\hline \multicolumn{2}{|c|}{$\begin{array}{l}\text { Probabilities of interruption and being stable at } \\
3 \text { months }\end{array}$} & Events & Pop. & $\alpha$ & $\beta$ & \\
\hline PLAI: initiation & Beta & 88 & 607 & 88 & 519 & \\
\hline \multirow[t]{2}{*}{ PLAI: prevention } & Beta & 28 & 206 & 28 & 178 & \\
\hline & & Events & Pop. & $\alpha$ & $\beta$ & \\
\hline RLAI: initiation & Beta & 89 & 613 & 89 & 524 & \\
\hline \multirow[t]{2}{*}{ RLAI: prevention } & Beta & 28 & 206 & 89 & 178 & \\
\hline & & Mean & Variance & $\alpha$ & $\beta$ & \\
\hline \multirow[t]{2}{*}{ ALAI: initiation } & Beta & 0.1767 & 0.0004 & 70.11 & 326.67 & \\
\hline & & Events & Pop. & $\alpha$ & $\beta$ & \\
\hline \multirow[t]{2}{*}{ ALAI: prevention } & Beta & 28 & 206 & 28 & 178 & \\
\hline & & Mean & Variance & $\alpha$ & $\beta$ & \\
\hline \multirow[t]{2}{*}{ OLAI: initiation } & Beta & 0.1412 & 0.0002 & 96.24 & 585.15 & \\
\hline & & Events & Pop. & $\alpha$ & $\beta$ & \\
\hline \multirow[t]{2}{*}{ OLAI: prevention } & Beta & 28 & 206 & 28 & 178 & \\
\hline & & Mean & Variance & $\alpha$ & $\beta$ & \\
\hline \multirow[t]{2}{*}{ HLAI: initiation } & Beta & 0.2203 & 0.0004 & 98.79 & 349.57 & \\
\hline & & Events & Pop. & $\alpha$ & $\beta$ & \\
\hline \multirow[t]{2}{*}{ HLAI: prevention } & Beta & 28 & 206 & 28 & 178 & \\
\hline & & Mean & Variance & $\alpha$ & $\beta$ & \\
\hline \multirow[t]{2}{*}{ OO: initiation } & Beta & 0.1412 & 0.0002 & 96.24 & 585.15 & \\
\hline & & Events & Pop. & $\alpha$ & $\beta$ & \\
\hline OO: prevention & Beta & 28 & 206 & 28 & 178 & \\
\hline \multicolumn{2}{|c|}{ Transition probabilities of stable pts } & Mean & Variance & $\alpha j$ & $\beta=1$ & \\
\hline $\begin{array}{l}\text { 1. Probability of being } \\
\text { stable without treatment }\end{array}$ & Dirichlet & 0.2307 & 0.0023 & 23.07 & 1 & Hypothesis: Var $=$ mean $/ 100$ \\
\hline $\begin{array}{l}\text { 2. Probability of initiating } \\
\text { the same antipsychotic } \\
\text { than the previous } \\
\text { treatment line }\end{array}$ & Dirichlet & 0.2307 & 0.0023 & 23.07 & 1 & Hypothesis: Var $=$ mean $/ 100$ \\
\hline \multirow{2}{*}{$\begin{array}{l}\text { 3. Probability of initiating a } \\
\text { new antipsychotic }\end{array}$} & Dirichlet & 0.2307 & 0.0023 & 23.07 & 1 & Hypothesis: Var $=$ mean $/ 100$ \\
\hline & & Mean & Variance & $\alpha$ & $\beta$ & \\
\hline
\end{tabular}


Table 11 continued

\begin{tabular}{|c|c|c|c|c|c|c|}
\hline \multirow{2}{*}{$\frac{\text { Input parameters }}{\begin{array}{l}\text { 4. Median time before } \\
\text { relapse }\end{array}}$} & \multirow{2}{*}{$\frac{\text { Distribution }}{\text { Gamma }}$} & \multicolumn{2}{|c|}{ PSA parameters } & \multirow[b]{2}{*}{45.5} & \multirow[b]{2}{*}{3.8} & \multirow[t]{2}{*}{ Comments } \\
\hline & & 172 & 25.5 & & & \\
\hline \multicolumn{7}{|l|}{ Probabilities of relapse } \\
\hline \multicolumn{2}{|c|}{ Probabilities of relapse at 3 months } & Events & Pop. & $\alpha$ & $\beta$ & \\
\hline \multirow[t]{2}{*}{ PLAI: initiation } & Beta & 40 & 607 & 40 & 567 & \\
\hline & & Moy/an & Var/an & $\alpha$ & $\beta$ & \\
\hline \multirow[t]{2}{*}{ PLAI: prevention } & Beta & 0.2915 & 0.0163 & 3.4092 & 8.2855 & \\
\hline & & Mean & Pop. & $\alpha$ & $\beta$ & \\
\hline \multirow[t]{2}{*}{ RLAI: initiation } & Beta & 43 & 613 & 43 & 570 & \\
\hline & & Mean/year & Var/an & $\alpha$ & $\beta$ & \\
\hline \multirow[t]{2}{*}{ RLAI: prevention } & Beta & 0.2915 & 0.0163 & 3.4092 & 8.2855 & \\
\hline & & Mean & Variance & $\alpha$ & $\beta$ & \\
\hline \multirow[t]{2}{*}{ ALAI: initiation } & Beta & 0.0820 & 0.0001 & 62.336 & 698.06 & \\
\hline & & Mean/year & Var/an & $\alpha$ & $\beta$ & \\
\hline \multirow[t]{2}{*}{ ALAI: prevention } & Beta & 0.2915 & 0.0163 & 3.4092 & 8.2855 & \\
\hline & & Mean & Variance & $\alpha$ & $\beta$ & \\
\hline \multirow[t]{2}{*}{ OLAI: initiation } & Beta & 0.0640 & 0.000 & 87.937 & 1285.1 & \\
\hline & & Mean/year & Var/an & $\alpha$ & $\beta$ & \\
\hline \multirow[t]{2}{*}{ OLAI: prevention } & Beta & 0.2915 & 0.0163 & 3.4092 & 8.2855 & \\
\hline & & Mean & Variance & $\alpha$ & $\beta$ & \\
\hline \multirow[t]{2}{*}{ HLAI: initiation } & Beta & 0.1052 & 0.0001 & 85.501 & 727.18 & \\
\hline & & Mean RR & Var RR & $\alpha$ & $\beta$ & \\
\hline \multirow[t]{2}{*}{ HLAI: prevention } & Beta & 0.5300 & 0.0115 & 10.971 & 9.7287 & \\
\hline & & Mean & Variance & $\alpha$ & $\beta$ & \\
\hline \multirow[t]{2}{*}{ OO: initiation } & Beta & 0.0640 & 0.000 & 87.937 & 1285.1 & \\
\hline & & Mean RR & Var RR & $\alpha$ & $\beta$ & \\
\hline OO: prevention & Beta & 0.6000 & 0.0183 & 7.2774 & 4.8516 & \\
\hline \multicolumn{2}{|c|}{ Proportions of pts in relapse leaving the hospital } & Mean & Variance & $\alpha j$ & $\beta=1$ & \\
\hline Within the 3 months & Dirichlet & 0.8493 & 0.0009 & 84.9315 & 1 & \\
\hline Between 3 and 6 months & Dirichlet & 0.1027 & 0.0006 & 10.274 & 1 & \\
\hline Between 6 and 9 months & Dirichlet & 0.0205 & 0.0001 & 2.0548 & 1 & \\
\hline Between 9 and 12 months & Dirichlet & 0.0068 & 0.000 & 0.6849 & 1 & \\
\hline After 12 months & Dirichlet & 0.0205 & 0.0001 & 2.0548 & 1 & \\
\hline \multicolumn{2}{|c|}{ Proportion of relapse requiring a hospitalisation } & Mean & Variance & $\alpha$ & $\beta$ & \\
\hline$\%$ hospitalised patients & Beta & 0.6700 & 0.0012 & 126.10 & 62.110 & Hypothesis: $\mathrm{SD}=10 \% *$ Mean \\
\hline \multicolumn{2}{|c|}{$\begin{array}{l}\text { Proportion of pts treated by the same antipsychotic than } \\
\text { the previous line after a relapse }\end{array}$} & Mean & Variance & $\alpha$ & $\beta$ & \\
\hline $\begin{array}{l}\% \text { of patients initiating the } \\
\text { same antipsychotic }\end{array}$ & Beta & 0.1500 & 0.0001 & 326.39 & 1849.5 & Hypothesis: $\mathrm{SD}=10 \% *$ Mean \\
\hline Probabilities of switch (due to & ck of tolerance) & & & & & \\
\hline Probabilities of switch at $3 n$ & nths & Events & Pop. & $\alpha$ & $\beta$ & \\
\hline PLAI: initiation & Beta & 20 & 607 & 20 & 587 & \\
\hline PLAI: prevention & Beta & 3 & 206 & 3 & 203 & \\
\hline & & Events & Pop. & $\alpha$ & $\beta$ & \\
\hline RLAI: initiation & Beta & 10 & 613 & 10 & 603 & \\
\hline RLAI: prevention & Beta & 3 & 206 & 3 & 203 & \\
\hline & & Mean & Variance & $\alpha$ & $\beta$ & \\
\hline ALAI: initiation & Beta & 0.0413 & 0.000 & 59.435 & 1378.1 & \\
\hline & & Events & Pop. & $\alpha$ & $\beta$ & \\
\hline
\end{tabular}


Table 11 continued

\begin{tabular}{|c|c|c|c|c|c|c|}
\hline \multirow{2}{*}{$\frac{\text { Input parameters }}{\text { ALAI: prevention }}$} & \multirow{2}{*}{$\begin{array}{l}\text { Distribution } \\
\text { Beta }\end{array}$} & \multicolumn{2}{|c|}{ PSA parameters } & & \multirow[t]{2}{*}{ Comments } \\
\hline & & 3 & 206 & 3 & 203 & \\
\hline & & Mean & Variance & $\alpha$ & $B$ & \\
\hline \multirow[t]{2}{*}{ OLAI: initiation } & Beta & 0.0320 & 0.0000 & 84.855 & 2567.5 & \\
\hline & & Events & Pop. & $\alpha$ & $\beta$ & \\
\hline \multirow[t]{2}{*}{ OLAI: prevention } & Beta & 3 & 206 & 3 & 203 & \\
\hline & & Mean & Variance & $\alpha$ & $\beta$ & \\
\hline \multirow[t]{2}{*}{ HLAI: initiation } & Beta & 0.0537 & 0.000 & 80.547 & 1418.4 & \\
\hline & & Events & Pop. & $\alpha$ & $\beta$ & \\
\hline \multirow[t]{2}{*}{ HLAI: prevention } & Beta & 3 & 206 & 3 & 203 & \\
\hline & & Mean & Variance & $\alpha$ & $\beta$ & \\
\hline \multirow[t]{2}{*}{ OO: initiation } & Beta & 0.0320 & 0.0000 & 84.855 & 2567.5 & \\
\hline & & Events & Pop. & $\alpha$ & $\beta$ & \\
\hline OO: prevention & Beta & 3 & 206 & 3 & 203 & \\
\hline \multicolumn{7}{|l|}{ Adverse events } \\
\hline \multicolumn{7}{|c|}{ Extrapyramidal syndrome (3-monthly probabilities) } \\
\hline $\begin{array}{l}\text { Initiation and prevention } \\
\text { phases }\end{array}$ & & Events & Pop. & $\alpha$ & $\beta$ & \\
\hline PLAI & Beta & 55 & 1000 & 55 & 945 & \\
\hline \multirow[t]{2}{*}{ RLAI } & Beta & 55 & 1000 & 55 & 945 & \\
\hline & & Mean & Variance & $\alpha$ & $\beta$ & \\
\hline ALAI & Beta & 0.0353 & 0.0001 & 8.6805 & 237.14 & \\
\hline OLAI & Beta & 0.0321 & 0.0001 & 17.849 & 538.03 & \\
\hline HLAI & Beta & 0.1328 & 0.0007 & 20.496 & 133.82 & \\
\hline $\mathrm{OO}$ & Beta & 0.0321 & 0.0001 & 17.849 & 538.03 & \\
\hline Clozapine & Beta & 0.0098 & 0.000 & 4.1602 & 420.47 & \\
\hline \multicolumn{7}{|c|}{ Tardive dyskinesia (3-monthly probabilities) } \\
\hline Initiation phase & & Events & Pop. & $\alpha$ & $\beta$ & \\
\hline PLAI & Beta & 1 & 606 & 1 & 605 & \\
\hline RLAI & Beta & 1 & 608 & 1 & 607 & \\
\hline ALAI & Beta & 1 & 606 & 1 & 605 & \\
\hline OLAI & Beta & 0 & 234 & 0 & 234 & \\
\hline HLAI & Beta & 5 & 219 & 5 & 214 & \\
\hline $\mathrm{OO}$ & Beta & 0 & 234 & 0 & 234 & \\
\hline Clozapine & Beta & 0 & 234 & 0 & 234 & \\
\hline Prevention phase & & Min & Max & $\alpha$ & $\beta$ & \\
\hline PLAI & Uniform & 0.0010 & 0.0100 & 0.0010 & 0.0100 & \\
\hline RLAI & Uniform & 0.0010 & 0.0100 & 0.0010 & 0.0100 & \\
\hline ALAI & Uniform & 0.0010 & 0.0100 & 0.0010 & 0.0100 & \\
\hline OLAI & Uniform & 0.0010 & 0.0100 & 0.0010 & 0.0100 & \\
\hline HLAI & Uniform & 0.0100 & 0.1000 & 0.0100 & 0.1000 & \\
\hline $\mathrm{OO}$ & Uniform & 0.0010 & 0.0100 & 0.0010 & 0.0100 & \\
\hline Clozapine & Uniform & 0.0000 & 0.0001 & 0.0000 & 0.0001 & \\
\hline
\end{tabular}


Table 11 continued

\begin{tabular}{|c|c|c|c|c|c|c|}
\hline Input parameters & Distribution & \multicolumn{2}{|c|}{ PSA parameters } & \multicolumn{3}{|r|}{ Comments } \\
\hline \multicolumn{7}{|c|}{ Diabetes (3-monthly probabilities) } \\
\hline Prevention phase & & Min & $\operatorname{Max}$ & $\alpha$ & $\beta$ & \multirow{8}{*}{$\begin{array}{l}\text { Hypothesis: ranges of the } \mathrm{SmPC} \\
\text { used for all treatments with } \\
\text { an uniform distribution }\end{array}$} \\
\hline PLAI & Uniform & 0.0010 & 0.0100 & 0.0010 & 0.0100 & \\
\hline RLAI & Uniform & 0.0010 & 0.0100 & 0.0010 & 0.0100 & \\
\hline ALAI & Uniform & 0.0100 & 0.1000 & 0.0100 & 0.100 & \\
\hline OLAI & Uniform & 0.0010 & 0.0100 & 0.0010 & 0.0100 & \\
\hline HLAI & Uniform & 0.0010 & 0.0100 & 0.0010 & 0.0100 & \\
\hline $\mathrm{OO}$ & Uniform & 0.0010 & 0.0100 & 0.0010 & 0.0100 & \\
\hline Clozapine & Uniform & 0.0001 & 0.0010 & 0.0001 & 0.0010 & \\
\hline \multicolumn{7}{|c|}{ Weight gained (3-monthly probabilities) } \\
\hline Initiation phase & & Events & Pop. & $\alpha$ & $\beta$ & \\
\hline PLAI & Beta & 55 & 1000 & 55 & 945 & \\
\hline RLAI & Beta & 55 & 1000 & 55 & 945 & \\
\hline \multirow[t]{2}{*}{ ALAI } & Beta & 55 & 1000 & 55 & 945 & \\
\hline & & Mean & Variance & $\alpha$ & $\beta$ & \\
\hline \multirow[t]{2}{*}{ OLAI } & Beta & 0.4680 & 0.0006 & 203.905 & 231.79 & \\
\hline & & Events & Pop. & $\alpha$ & $\beta$ & \\
\hline \multirow[t]{2}{*}{ HLAI } & Beta & 55 & 1000 & 55 & 945 & \\
\hline & & Mean & Variance & $\alpha$ & $\beta$ & \\
\hline \multirow[t]{2}{*}{$\mathrm{OO}$} & Beta & 0.4680 & 0.0006 & 203.905 & 231.79 & \\
\hline & & Events & Pop. & $\alpha$ & $\beta$ & \\
\hline Clozapine & Beta & 55 & 1000 & 55 & 945 & \\
\hline Prevention phase & & Min & $\operatorname{Max}$ & $\alpha$ & $\beta$ & \\
\hline PLAI & Uniform & 0.0100 & 0.1000 & 0.0100 & 0.1000 & \\
\hline RLAI & Uniform & 0.0100 & 0.1000 & 0.0100 & 0.1000 & \\
\hline ALAI & Uniform & 0.0100 & 0.1000 & 0.0100 & 0.1000 & \\
\hline OLAI & Uniform & 0.1000 & 1.0000 & 0.1000 & 1.0000 & \\
\hline HLAI & Uniform & 0.0100 & 0.1000 & 0.0100 & 0.1000 & \\
\hline $\mathrm{OO}$ & Uniform & 0.0100 & 0.1000 & 0.0100 & 0.1000 & \\
\hline Clozapine & Uniform & 0.0100 & 0.1000 & 0.0100 & 0.1000 & \\
\hline \multicolumn{7}{|l|}{ Costs and resources } \\
\hline \multicolumn{7}{|c|}{ Initiation of a new treatment in case of interruption or switch (relapse excluded) } \\
\hline $\begin{array}{l}\text { PLAI, RLAI, AL } \\
\text { HLAI, OO }\end{array}$ & & Mean & Variance & $\alpha$ & $\beta$ & \\
\hline Outpatient care & Beta & 0.9000 & 0.0021 & 37.5160 & 4.1684 & \\
\hline Clozapine & & Mean & Variance & $\alpha$ & $\beta$ & \\
\hline Outpatient care & Beta & 0.1000 & 0.000 & 645.644 & 3110.80 & \\
\hline \multicolumn{2}{|c|}{$\begin{array}{l}\text { Number of hospitalised weeks required after the } \\
\text { stabilisation phase for the initiation of each } \\
\text { antipsychotic }\end{array}$} & Min & Max & $\alpha$ & $\beta$ & \\
\hline PLAI & Triangular & -1 & 1 & 0 & 2 & \\
\hline RLAI & Triangular & -1 & 1 & 1 & 3 & \\
\hline ALAI & Triangular & -1 & 1 & 1 & 3 & \\
\hline OLAI & Triangular & -1 & 1 & 1 & 3 & \\
\hline HLAI & Triangular & -1 & 1 & 0 & 2 & \\
\hline $\mathrm{OO}$ & Triangular & -1 & 1 & 0 & 1 & \\
\hline Clozapine & Triangular & -1 & 1 & 0 & 1 & \\
\hline
\end{tabular}


Table 11 continued

\begin{tabular}{|c|c|c|c|c|c|c|}
\hline \multirow{2}{*}{$\frac{\text { Input parameters }}{\text { Hospitalisation cost (1 day) }}$} & \multirow[t]{2}{*}{ Distribution } & \multicolumn{4}{|c|}{ PSA parameters } & \multirow[t]{2}{*}{ Comments } \\
\hline & & $\operatorname{Min}(-\%)$ & $\operatorname{Max}(+\%)$ & $\alpha$ & $\beta$ & \\
\hline Initiation phase & Triangular & -1 & 1 & 218 & 655 & \\
\hline Relapse & Triangular & -1 & 1 & 218 & 655 & \\
\hline \multicolumn{2}{|c|}{ Mean duration of stabilisation (days) at the hospital } & Mean & $\sigma$ & $\alpha$ & $\beta$ & \\
\hline Within 3 months & Trunc.normal & 30 & 33 & 0 & 90 & Hypothesis: \\
\hline Between 3 and 6 months & Trunc.normal & 135 & 33 & 90 & 180 & \\
\hline Between 6 and 9 months & Trunc.normal & 225 & 33 & 180 & 270 & \\
\hline Between 9 and 12 months & Trunc.normal & 315 & 33 & 270 & 360 & \\
\hline After 12 months & Trunc.normal & 715 & 240 & 360 & 1800 & \\
\hline \multicolumn{2}{|c|}{ Maintenance costs: outpatient care } & $\operatorname{Min}(-\%)$ & $\operatorname{Max}(+\%)$ & $\alpha$ & $\beta$ & \\
\hline Annual cost & Triangular & -1 & 1 & 531 & 1592 & \\
\hline Additional psychiatrist visits & & Min & Max & $\alpha$ & $\beta$ & \\
\hline Initiation phase & Triangular & -1 & 1 & 5 & 7 & \\
\hline Relapse & Triangular & -1 & 1 & 5 & 7 & \\
\hline \multicolumn{7}{|c|}{ Resources and costs associated with adverse events } \\
\hline Extrapyramidal syndrome & & Min & Max & $\alpha$ & $\beta$ & \\
\hline GP & Triangular & -1 & 1 & 0 & 2 & \\
\hline Psychiatrist & Triangular & -1 & 1 & 0 & 2 & \\
\hline Tardive dyskinesia & & Min & Max & $a$ & $B$ & \\
\hline GP & Triangular & -1 & 1 & 0 & 2 & \\
\hline Psychiatrist & Triangular & -1 & 1 & 0 & 2 & \\
\hline Neurologist & Triangular & -1 & 1 & 0 & 2 & \\
\hline Diabetes & & $\operatorname{Min}(-\%)$ & $\operatorname{Max}(+\%)$ & $\alpha$ & $\beta$ & \\
\hline Global cost (3 months) & Triangular & -1 & 1 & 659 & 1977 & \\
\hline Weight gained & & Min & Max & $\alpha$ & $\beta$ & \\
\hline GP & Triangular & -1 & 1 & 0 & 2 & \\
\hline Psychiatrist & Triangular & -1 & 1 & 0 & 2 & \\
\hline Nutritionist & Triangular & -1 & 1 & 0 & 2 & \\
\hline Endocrinologist & Triangular & -1 & 1 & 0 & 2 & \\
\hline Blood glucose analysis & Triangular & -1 & 1 & 0 & 2 & \\
\hline $\begin{array}{l}\text { Lipid abnormality } \\
\text { investigations }\end{array}$ & Triangular & -1 & 1 & 0 & 2 & \\
\hline \multicolumn{7}{|l|}{ Utility data } \\
\hline Utility data by health states & & Mean & $\mathrm{SD}$ & $\mu$ & $\sigma$ & \\
\hline $\begin{array}{l}\text { Stable (without adverse } \\
\text { events) }\end{array}$ & Log-normal & 0.23 & 0.01 & -1.57 & 0.45 & Hypothesis: SD $=10 \% \times$ mean \\
\hline $\begin{array}{l}\text { Relapse (without } \\
\text { hospitalisation) }\end{array}$ & Log-normal & 0.19 & 0.01 & -1.78 & 0.49 & Hypothesis: SD $=10 \% \times$ mean \\
\hline $\begin{array}{l}\text { Relapse (requiring } \\
\text { hospitalisation) }\end{array}$ & Log-normal & 0.15 & 0.01 & -2.04 & 0.54 & Hypothesis: $\mathrm{SD}=10 \% \times$ mean \\
\hline \multicolumn{2}{|c|}{ Utility decrement by adverse events } & Mean & SD & $\mu$ & $\sigma$ & \\
\hline Extrapyramidal syndrome & Log-normal & 0.0493 & 0.0025 & -3.3663 & 0.8432 & Hypothesis: $\mathrm{SD}=10 \% \times$ mean \\
\hline Tardive dyskinesia & Log-normal & 0.0493 & 0.0025 & -3.3663 & 0.8432 & Hypothesis: $\mathrm{SD}=10 \% \times$ mean \\
\hline Diabetes & Log-normal & 0.0375 & 0.0019 & -3.7129 & 0.9268 & Hypothesis: $\mathrm{SD}=10 \% \times$ mean \\
\hline Weight gained & Log-normal & 0.0235 & 0.0012 & -4.3278 & 1.0743 & Hypothesis: $\mathrm{SD}=10 \% \times$ mean \\
\hline
\end{tabular}

$A L A I$ aripiprazole long-acting injectable, $A P$ antipsychotic first-line, $H L A I$ haloperidol long-acting injectable, Max maximum, Min minimum, $O L A I$ olanzapine long-acting injectable, $O O$ oral olanzapine, PLAI paliperidone long-acting injectable, Pop population, PSA probabilistic sensitivity analysis, $p t s$ patients, $R L A I$ risperidone long-acting injectable, $S D$ standard deviation, $S M R$ standardised mortality rate, Var variance 
Table 12 Unit costs by cycle and health state per patient, and distribution by cost category, for each treatment: input parameters

\begin{tabular}{|c|c|c|c|c|c|c|c|c|}
\hline & \multicolumn{3}{|l|}{ Stable } & \multicolumn{5}{|l|}{ Relapse } \\
\hline & Initiation & Prevention & $\begin{array}{l}\text { Non- } \\
\text { treated }\end{array}$ & $\begin{array}{l}\text { With hospi. } \\
3 \text { months }\end{array}$ & $\begin{array}{l}\text { With hospi. } \\
6 \text { months }\end{array}$ & $\begin{array}{l}\text { With hospi. } \\
9 \text { months }\end{array}$ & $\begin{array}{l}\text { With hospi. } \\
>12 \text { months }\end{array}$ & $\begin{array}{l}\text { Without } \\
\text { hospi. }\end{array}$ \\
\hline \multicolumn{9}{|l|}{ PLAI } \\
\hline Costs by cycle & $€ 4040$ & $€ 1039$ & $€ 265$ & $€ 21,251$ & $€ 29,174$ & $€ 32,931$ & $€ 268,658$ & $€ 1601$ \\
\hline \multicolumn{9}{|c|}{ Distribution by cost category } \\
\hline Medication & $12.41 \%$ & $72.42 \%$ & $0.00 \%$ & $1.19 \%$ & $0.49 \%$ & $0.27 \%$ & $0.00 \%$ & $68.08 \%$ \\
\hline Administration & $0.35 \%$ & $2.02 \%$ & $0.00 \%$ & $0.03 \%$ & $0.01 \%$ & $0.01 \%$ & $0.00 \%$ & $1.47 \%$ \\
\hline Tests & $0.00 \%$ & $0.00 \%$ & $0.00 \%$ & $0.00 \%$ & $0.00 \%$ & $0.00 \%$ & $0.00 \%$ & $0.00 \%$ \\
\hline Hospitalisation & $75.68 \%$ & $0.00 \%$ & $0.00 \%$ & $97.67 \%$ & $99.01 \%$ & $99.48 \%$ & $100.00 \%$ & $0.00 \%$ \\
\hline Consultation & $5.49 \%$ & $0.00 \%$ & $0.00 \%$ & $0.52 \%$ & $0.25 \%$ & $0.11 \%$ & $0.00 \%$ & $13.87 \%$ \\
\hline Maintenance & $6.06 \%$ & $25.55 \%$ & $100.00 \%$ & $0.58 \%$ & $0.24 \%$ & $0.13 \%$ & $0.00 \%$ & $16.58 \%$ \\
\hline \multicolumn{9}{|l|}{ RLAI } \\
\hline Total costs & $€ 7084$ & $€ 1093$ & $€ 265$ & $€ 21,679$ & $€ 29,500$ & $€ 33,140$ & $€ 268,658$ & $€ 1534$ \\
\hline \multicolumn{9}{|c|}{ Distribution by cost category } \\
\hline Medication & $7.49 \%$ & $71.86 \%$ & $0.00 \%$ & $1.32 \%$ & $0.54 \%$ & $0.30 \%$ & $0.00 \%$ & $66.55 \%$ \\
\hline Administration & $0.40 \%$ & $3.84 \%$ & $0.00 \%$ & $0.07 \%$ & $0.03 \%$ & $0.02 \%$ & $0.00 \%$ & $1.67 \%$ \\
\hline Tests & $0.00 \%$ & $0.00 \%$ & $0.00 \%$ & $0.00 \%$ & $0.00 \%$ & $0.00 \%$ & $0.00 \%$ & $0.00 \%$ \\
\hline Hospitalisation & $86.34 \%$ & $0.00 \%$ & $0.00 \%$ & $97.54 \%$ & $98.97 \%$ & $99.44 \%$ & $100.00 \%$ & $0.00 \%$ \\
\hline Consultation & $2.61 \%$ & $0.00 \%$ & $0.00 \%$ & $0.51 \%$ & $0.23 \%$ & $0.11 \%$ & $0.00 \%$ & $14.47 \%$ \\
\hline Maintenance & $3.17 \%$ & $24.29 \%$ & $100.00 \%$ & $0.56 \%$ & $0.23 \%$ & $0.13 \%$ & $0.00 \%$ & $17.30 \%$ \\
\hline \multicolumn{9}{|l|}{ ALAI } \\
\hline Total costs & $€ 7076$ & $€ 1092$ & $€ 265$ & $€ 21,675$ & $€ 29,498$ & $€ 33,139$ & $€ 268,658$ & $€ 1538$ \\
\hline \multicolumn{9}{|c|}{ Distribution by cost category } \\
\hline Medication & $7.59 \%$ & $73.77 \%$ & $0.00 \%$ & $1.34 \%$ & $0.55 \%$ & $0.31 \%$ & $0.00 \%$ & $66.84 \%$ \\
\hline Administration & $0.20 \%$ & $1.92 \%$ & $0.00 \%$ & $0.03 \%$ & $0.01 \%$ & $0.01 \%$ & $0.00 \%$ & $1.46 \%$ \\
\hline Tests & $0.00 \%$ & $0.00 \%$ & $0.00 \%$ & $0.00 \%$ & $0.00 \%$ & $0.00 \%$ & $0.00 \%$ & $0.00 \%$ \\
\hline Hospitalisation & $86.43 \%$ & $0.00 \%$ & $0.00 \%$ & $97.55 \%$ & $98.98 \%$ & $99.45 \%$ & $100.00 \%$ & $0.00 \%$ \\
\hline Consultation & $2.61 \%$ & $0.00 \%$ & $0.00 \%$ & $0.51 \%$ & $0.23 \%$ & $0.11 \%$ & $0.00 \%$ & $14.44 \%$ \\
\hline Maintenance & $3.17 \%$ & $24.30 \%$ & $100.00 \%$ & $0.56 \%$ & $0.23 \%$ & $0.13 \%$ & $0.00 \%$ & $17.26 \%$ \\
\hline \multicolumn{9}{|l|}{ OLAI } \\
\hline Total costs & $€ 4399$ & $€ 1576$ & $€ 265$ & $€ 21,433$ & $€ 29,276$ & $€ 32,995$ & $€ 268,658$ & $€ 1603$ \\
\hline \multicolumn{9}{|c|}{ Distribution by cost category } \\
\hline Medication & $19.86 \%$ & $83.16 \%$ & $0.00 \%$ & $2.06 \%$ & $0.85 \%$ & $0.47 \%$ & $0.00 \%$ & $68.39 \%$ \\
\hline Administration & $0.00 \%$ & $0.00 \%$ & $0.00 \%$ & $0.00 \%$ & $0.00 \%$ & $0.00 \%$ & $0.00 \%$ & $1.21 \%$ \\
\hline Tests & $0.00 \%$ & $0.00 \%$ & $0.00 \%$ & $0.00 \%$ & $0.00 \%$ & $0.00 \%$ & $0.00 \%$ & $0.00 \%$ \\
\hline Hospitalisation & $69.52 \%$ & $0.00 \%$ & $0.00 \%$ & $96.84 \%$ & $98.66 \%$ & $99.28 \%$ & $100.00 \%$ & $0.00 \%$ \\
\hline Consultation & $5.05 \%$ & $0.00 \%$ & $0.00 \%$ & $0.52 \%$ & $0.25 \%$ & $0.11 \%$ & $0.00 \%$ & $13.85 \%$ \\
\hline Maintenance & $5.57 \%$ & $16.84 \%$ & $100.00 \%$ & $0.58 \%$ & $0.24 \%$ & $0.13 \%$ & $0.00 \%$ & $16.55 \%$ \\
\hline \multicolumn{9}{|l|}{ HLAI } \\
\hline Total costs & $€ 3581$ & $€ 336$ & $€ 265$ & $€ 21,019$ & $€ 29,043$ & $€ 32,849$ & $€ 268,658$ & $€ 1417$ \\
\hline \multicolumn{9}{|c|}{ Distribution by cost category } \\
\hline Medication & $1.38 \%$ & $14.76 \%$ & $0.00 \%$ & $0.12 \%$ & $0.05 \%$ & $0.03 \%$ & $0.00 \%$ & $64.02 \%$ \\
\hline Administration & $0.20 \%$ & $6.25 \%$ & $0.00 \%$ & $0.02 \%$ & $0.01 \%$ & $0.00 \%$ & $0.00 \%$ & $1.59 \%$ \\
\hline Tests & $0.00 \%$ & $0.00 \%$ & $0.00 \%$ & $0.00 \%$ & $0.00 \%$ & $0.00 \%$ & $0.00 \%$ & $0.00 \%$ \\
\hline Hospitalisation & $85.38 \%$ & $0.00 \%$ & $0.00 \%$ & $98.75 \%$ & $99.45 \%$ & $99.72 \%$ & $100.00 \%$ & $0.00 \%$ \\
\hline Consultation & $6.20 \%$ & $0.00 \%$ & $0.00 \%$ & $0.53 \%$ & $0.25 \%$ & $0.11 \%$ & $0.00 \%$ & $15.66 \%$ \\
\hline Maintenance & $6.84 \%$ & $78.99 \%$ & $100.00 \%$ & $0.59 \%$ & $0.24 \%$ & $0.13 \%$ & $0.00 \%$ & $18.73 \%$ \\
\hline
\end{tabular}


Table 12 continued

\begin{tabular}{|c|c|c|c|c|c|c|c|c|}
\hline & \multicolumn{3}{|l|}{ Stable } & \multicolumn{5}{|l|}{ Relapse } \\
\hline & Initiation & Prevention & $\begin{array}{l}\text { Non- } \\
\text { treated }\end{array}$ & $\begin{array}{l}\text { With hospi. } \\
3 \text { months }\end{array}$ & $\begin{array}{l}\text { With hospi. } \\
6 \text { months }\end{array}$ & $\begin{array}{l}\text { With hospi. } \\
9 \text { months }\end{array}$ & $\begin{array}{l}\text { With hospi. } \\
>12 \text { months }\end{array}$ & $\begin{array}{l}\text { Without } \\
\text { hospi. }\end{array}$ \\
\hline \multicolumn{9}{|l|}{$\mathrm{OO}$} \\
\hline Total costs & $€ 628$ & $€ 406$ & $€ 265$ & $€ 20,604$ & $€ 28,717$ & $€ 32,644$ & $€ 268,658$ & $€ 1428$ \\
\hline \multicolumn{9}{|c|}{ Distribution by cost category } \\
\hline Medication & $22.40 \%$ & $34.65 \%$ & $0.00 \%$ & $0.00 \%$ & $0.00 \%$ & $0.00 \%$ & $0.00 \%$ & $64.51 \%$ \\
\hline Administration & $0.00 \%$ & $0.00 \%$ & $0.00 \%$ & $0.00 \%$ & $0.00 \%$ & $0.00 \%$ & $0.00 \%$ & $1.35 \%$ \\
\hline Tests & $0.00 \%$ & $0.00 \%$ & $0.00 \%$ & $0.00 \%$ & $0.00 \%$ & $0.00 \%$ & $0.00 \%$ & $0.00 \%$ \\
\hline Hospitalisation & $0.00 \%$ & $0.00 \%$ & $0.00 \%$ & $98.85 \%$ & $99.49 \%$ & $99.75 \%$ & $100.00 \%$ & $0.00 \%$ \\
\hline Consultation & $35.34 \%$ & $0.00 \%$ & $0.00 \%$ & $0.54 \%$ & $0.26 \%$ & $0.11 \%$ & $0.00 \%$ & $15.55 \%$ \\
\hline Maintenance & $42.25 \%$ & $65.35 \%$ & $100.00 \%$ & $0.61 \%$ & $0.25 \%$ & $0.14 \%$ & $0.00 \%$ & $18.59 \%$ \\
\hline \multicolumn{9}{|l|}{ 2nd line } \\
\hline Total costs & $€ 1977$ & $€ 1200$ & $€ 265$ & $€ 18,286$ & $€ 26,810$ & $€ 31,478$ & $€ 268,744$ & $€ 858$ \\
\hline \multicolumn{9}{|c|}{ Distribution by cost category } \\
\hline Medication & $51.29 \%$ & $76.13 \%$ & $0.00 \%$ & $1.62 \%$ & $0.66 \%$ & $0.35 \%$ & $0.00 \%$ & $32.69 \%$ \\
\hline Administration & $1.11 \%$ & $1.75 \%$ & $0.00 \%$ & $0.05 \%$ & $0.02 \%$ & $0.01 \%$ & $0.00 \%$ & $0.40 \%$ \\
\hline Tests & $0.00 \%$ & $0.00 \%$ & $0.00 \%$ & $0.47 \%$ & $0.32 \%$ & $0.27 \%$ & $0.03 \%$ & $10.09 \%$ \\
\hline Hospitalisation & $23.20 \%$ & $0.00 \%$ & $0.00 \%$ & $96.46 \%$ & $98.40 \%$ & $99.07 \%$ & $99.97 \%$ & $0.00 \%$ \\
\hline Consultation & $11.14 \%$ & $0.00 \%$ & $0.00 \%$ & $0.61 \%$ & $0.28 \%$ & $0.12 \%$ & $0.00 \%$ & $25.88 \%$ \\
\hline Maintenance & $13.27 \%$ & $22.12 \%$ & $100.00 \%$ & $0.79 \%$ & $0.32 \%$ & $0.17 \%$ & $0.00 \%$ & $30.94 \%$ \\
\hline \multicolumn{9}{|c|}{ 3rd line (clozapine) } \\
\hline Total costs & $€ 733$ & $€ 444$ & $€ 265$ & $€ 17,729$ & $€ 26,366$ & $€ 31,204$ & $€ 268,760$ & $€ 732$ \\
\hline \multicolumn{9}{|c|}{ Distribution by cost category } \\
\hline Medication & $19.66 \%$ & $34.93 \%$ & $0.00 \%$ & $1.72 \%$ & $0.69 \%$ & $0.37 \%$ & $0.00 \%$ & $19.53 \%$ \\
\hline Administration & $0.00 \%$ & $0.00 \%$ & $0.00 \%$ & $0.05 \%$ & $0.02 \%$ & $0.01 \%$ & $0.00 \%$ & $0.00 \%$ \\
\hline Tests & $13.88 \%$ & $5.29 \%$ & $0.00 \%$ & $0.57 \%$ & $0.39 \%$ & $0.33 \%$ & $0.04 \%$ & $13.90 \%$ \\
\hline Hospitalisation & $0.00 \%$ & $0.00 \%$ & $0.00 \%$ & $96.20 \%$ & $98.28 \%$ & $99.00 \%$ & $99.96 \%$ & $0.00 \%$ \\
\hline Consultation & $30.27 \%$ & $0.00 \%$ & $0.00 \%$ & $0.63 \%$ & $0.28 \%$ & $0.12 \%$ & $0.00 \%$ & $30.32 \%$ \\
\hline Maintenance & $36.19 \%$ & $59.78 \%$ & $100.00 \%$ & $0.84 \%$ & $0.34 \%$ & $0.18 \%$ & $0.00 \%$ & $36.25 \%$ \\
\hline
\end{tabular}

$A L A I$ aripiprazole long-acting injectable, HLAI haloperidol long-acting injectable, Hospi. hospitalisation, OLAI olanzapine long-acting injectable, $O O$ oral olanzapine, PLAI paliperidone long-acting injectable, RLAI risperidone long-acting injectable

\section{References}

1. World Health Organisation (WHO). Schizophrenia: Fact sheet $\mathrm{N}^{\circ} 397$ [database on the Internet] 2014 [cited 04/11/2014]. Available from: http://www.who.int/mediacentre/factsheets/ fs $397 / \mathrm{en} /$

2. World Health Organization (WHO). Schizophrenia and public health. 1996.

3. Haute Autorité de Santé (HAS). Commission de la Transparence-Avis du $1^{\text {er }}$ février 2012 : XEPLION. 2012.

4. Eaton WW, Martins SS, Nestadt G, et al. The burden of mental disorders. Epidemiol Rev. 2008;30:1-14.

5. McGrath J, Saha S, Chant D, et al. Schizophrenia: a concise overview of incidence, prevalence, and mortality. Epidemiol Rev. 2008:30:67-76.

6. Switaj P, Anczewska M, Chrostek A, et al. Disability and schizophrenia: a systematic review of experienced psychosocial difficulties. BMC Psychiatry. 2012;12(1):193.

7. Direction Générale de la Santé, INSERM. Rapport du GTNDO: Analyse des connaissances disponibles sur des problèmes de santé sélectionnés, leurs déterminants, et les stratégies de santé publique-Définition d'objectifs. 2003.

8. World Health Organization (WHO). The global burden of disease: 2004 update. 2008.

9. Ministère du Travail de l'Emploi et de la Santé. Plan psychiatrique et santé mentale 2011-2015. 2012.

10. Andlin-Sobocki P, Jonsson B, Wittchen HU, et al. Cost of disorders of the brain in Europe. Eur J Neurol. 2005;12(Suppl 1): $1-27$.

11. Llorca PM. https://www.orpha.net/data/patho/FR/fr-schizo.pdf. Encyclopénie Orphanet. 2004.

12. Haute Autorité de Santé (HAS). Guide ALD 23 «Schizophrénies». 2007.

13. Haute Autorité de Santé (HAS). Commission de la Transparence-Avis du 23 septembre 2009: ZYPADHERA. 2009.

14. Haute Autorité de Santé (HAS). Commission de la Transparence-Avis du 5 mai 2010: RISPERDALCONSTA L.P. 2010.

15. The Court of Auditors. L'organisation des soins psychiatriques: les effets du plan "psychiatrie et santé mentale". 2011. 
16. Leucht S, Corves C, Arbter D, et al. Second-generation versus first-generation antipsychotic drugs for schizophrenia: a metaanalysis. Lancet. 2009;373(9657):31-41.

17. Hartling L, Abou-Setta AM, Dursun S, et al. Antipsychotics in adults with schizophrenia: comparative effectiveness of firstgeneration versus second-generation medications: a systematic review and meta-analysis. Ann Intern Med. 2012;157(7):498511.

18. Kishimoto T, Agarwal V, Kishi T, et al. Relapse prevention in schizophrenia: a systematic review and meta-analysis of secondgeneration antipsychotics versus first-generation antipsychotics. Mol Psychiatry. 2013;18(1):53-66.

19. Haute Autorité de Santé (HAS). Commission de la Transparence-Avis du 30 novembre 2011. 2011.

20. Llorca PM, Abbar M, Courtet P, et al. Guidelines for the use and management of long-acting injectable antipsychotics in serious mental illness. BMC Psychiatry. 2013;13:340.

21. Kane JM, Garcia-Ribera C. Clinical guideline recommendations for antipsychotic long-acting injections. Br J Psychiatry Suppl. 2009;52:S63-7.

22. Haddad PM, Taylor M, Niaz OS. First-generation antipsychotic long-acting injections $\mathrm{v}$. oral antipsychotics in schizophrenia: systematic review of randomised controlled trials and observational studies. Br J Psychiatry Suppl. 2009;52:S20-8.

23. Lee JJY, Gauthier A, Curtis S, Musingarimi P, Price M. Cost Effectiveness of Paliperidone Palmitate in National Health Service (NHS) Wales: a cost utility analysis based on the National Institute for Health and Care Excellence (NICE) Core Model for the Management of Schizophrenia. Value Health. 2013;16(7):A549.

24. Raymond S, Martin M, Netillard C, et al. Schizophrénie : évaluation du coût de la prise en charge. Journal d'Economie Médicale. 2009;27(7-8):421-33.

25. Llorca PM, Miadi-Fargier H, Lancon C, et al. Cost-effectiveness analysis of schizophrenic patient care settings: impact of an atypical antipsychotic under long-acting injection formulation. Encephale. 2005;31(2):235-46.

26. Grimaldi-Bensouda L, Rouillon F, Astruc B, et al. Does long-acting injectable risperidone make a difference to the real-life treatment of schizophrenia? Results of the Cohort for the General study of Schizophrenia (CGS). Schizophr Res. 2012;134(2-3):187-94.

27. Haute Autorité de Santé (HAS). A methodological guidechoices in methods for economic evaluation. 2012.

28. Mehnert A, Nicholl D, Pudas H, et al. Cost effectiveness of paliperidone palmitate versus risperidone long-acting injectable and olanzapine pamoate for the treatment of patients with schizophrenia in Sweden. J Med Econ. 2012;15(5):844-61.

29. Zeidler J, Mahlich J, Greiner W, et al. Cost effectiveness of paliperidone palmitate for the treatment of schizophrenia in Germany. Appl Health Econ Health Policy. 2013;11(5):509-21.

30. Samalin L, Abbar M, Courtet P, et al. French Society for Biological Psychiatry and Neuropsychopharmacology task force: formal consensus for the prescription of depot antipsychotics. Encephale. 2013;39(Suppl 4):189-203.

31. RISPERDALCONSTA: summary of product characteristics [database on the Internet] 2014 [cited 07/11/2014]. Available from: http://agence-prd.ansm.sante.fr/php/ecodex/frames.php? specid $=68901873 \&$ typedoc $=$ R\&ref $=$ R0241528.htm.

32. XEPLION: summary of product characteristics. [database on the Internet] 2014 [cited 07/11/2014]. Available from: http://www. ema.europa.eu/docs/en_GB/document_library/EPAR_-_Product_ Information/human/002105/WC500103317.pdf.

33. ZYPADHERA: summary of product characteristics. [database on the Internet]2014 [cited 07/11/2014]. Available from: http:// www.ema.europa.eu/ema/index.jsp?curl=pages/medicines/human/
medicines/000890/human_med_001188.jsp\&mid=WC0b01ac $058001 \mathrm{~d} 124$

34. ABILIFY MAINTENA: summary of product characteristics. [database on the Internet] 2014 [cited 07/11/2014]. Available from: http://www.ema.europa.eu/ema/index.jsp?curl=pages/ medicines/human/medicines/002755/human_med_001711.jsp\& mid=WC0b01 ac058001d 124 .

35. HALDOL DECANOAS: summary of product characteristics [database on the Internet] 2014 [cited 07/11/2014]. Available from: http://agence-prd.ansm.sante.fr/php/ecodex/frames.php? specid=61505095\&typedoc=R\&ref=R0223383.htm.

36. ZYPREXA: summary of product characteristics. [database on the Internet] 2014 [cited 07/11/2014]. Available from: http://www. ema.europa.eu/ema/index.jsp?curl=pages/medicines/human/ medicines/000115/human_med_001189.jsp\&mid=WC0b01ac0 $58001 \mathrm{~d} 124$.

37. Stahl SM, Morrissette DA, Citrome L, et al. "Meta-guidelines" for the management of patients with schizophrenia. CNS Spectr. 2013;18(3):150-62.

38. Hough D, Gopal S, Vijapurkar U, et al. Paliperidone palmitate maintenance treatment in delaying the time-to-relapse in patients with schizophrenia: a randomized, double-blind, placebo-controlled study. Schizophr Res. 2010;116(2-3):107-17.

39. Pandina G, Lane R, Gopal S, et al. A double-blind study of paliperidone palmitate and risperidone long-acting injectable in adults with schizophrenia. Prog Neuropsychopharmacol Biol Psychiatry. 2011;35(1):218-26.

40. Leucht S, Cipriani A, Spineli L, et al. Comparative efficacy and tolerability of 15 antipsychotic drugs in schizophrenia: a multiple-treatments meta-analysis. Lancet. 2013;382(9896):951-62.

41. Briggs A, Wild D, Lees M, et al. Impact of schizophrenia and schizophrenia treatment-related adverse events on quality of life: direct utility elicitation. Health Qual Life Outcomes. 2008;6:105.

42. Chue P, Eerdekens M, Augustyns I, et al. Comparative efficacy and safety of long-acting risperidone and risperidone oral tablets. Eur Neuropsychopharmacol J Eur Coll Neuropsychopharmacol. 2005;15(1):111-7.

43. Fusar-Poli P, Kempton MJ, Rosenheck RA. Efficacy and safety of second-generation long-acting injections in schizophrenia: a meta-analysis of randomized-controlled trials. Int Clin Psychopharmacol. 2013;28(2):57-66.

44. Zhornitsky S, Stip E. Oral versus long-acting injectable antipsychotics in the treatment of schizophrenia and special populations at risk for treatment nonadherence: a systematic review. Schizophr Res Treatment. 2012;2012:407171.

45. Olivares JM, Sermon J, Hemels M, et al. Definitions and drivers of relapse in patients with schizophrenia: a systematic literature review. Ann Gen Psychiatry. 2013;12(1):32.

46. CHU Clermont-Ferrand. CHU Request for hospitalisation duration: patients hospitalisés en 2012 et 2013 en Psychiatrie B, avec code diagnostique F200 à 209 ou F220 à F229. 2014.

47. Kasper S, Rosillon D, Duchesne I, et al. Risperidone olanzapine drug outcomes studies in schizophrenia (RODOS): efficacy and tolerability results of an international naturalistic study. Int Clin Psychopharmacol. 2001;16(4):179-87.

48. Saha S, Chant D, McGrath J. A systematic review of mortality in schizophrenia: is the differential mortality gap worsening over time? Arch Gen Psychiatry. 2007;64(10):1123-31.

49. Bralet MC, Yon V, Loas G, et al. Cause of mortality in schizophrenic patients: prospective study of years of a cohort of 150 chronic schizophrenic patients. Encephale. 2000;26(6):32-41.

50. Casadebaig F, Philippe A. Mortality in schizophrenic patients. 3 years follow-up of a cohort. Encephale. 1999;25(4):329-37.

51. Hoang U, Stewart R, Goldacre MJ. Mortality after hospital discharge for people with schizophrenia or bipolar disorder: 
retrospective study of linked English hospital episode statistics, 1999-2006. BMJ. 2011;343:d5422.

52. Indice à la consommation depuis 2000. [database on the Internet] 2015 [cited 29/01/2015].

53. French Health Insurance (Assurance Maladie). AMELIE-Bases des Médicaments et Informations Tarifaires. 2015. 02/01/2015.

54. Clozapine: summary of product characteristics [database on the Internet] 2014 [cited 07/11/2014]. Available from: http://agenceprd.ansm. sante.fr/php/ecodex/frames.php?specid $=64814983 \&$ typedoc $=$ R\&ref $=$ R0213721.htm.

55. French Health Insurance (Assurance Maladie). AMELIE - Tarifs conventionnels des médecins spécialiste [database on the Internet]. 2015. Available from: http://www.ameli.fr/professionnelsde-sante/medecins/votre-convention/tarifs/index.php.

56. Costs of ALD in 2009. [database on the Internet] 2014. Available from: http://www.ameli.fr/l-assurance-maladie/statistiques-etpublications/donnees-statistiques/affection-de-longue-duree-ald/ cout/cout-des-ald-en-2009.php.

57. Court of Auditores (Cour des comptes). L'organisation des soins psychiatriques : les effets du plan "psychiatrie et santé mentale" [2005-2010]. 2011; Available from: http://www.sante.gouv.fr/ IMG/pdf/L_organisation_des_soins_psychiatriques_les_effets_ du_plan_Psychiatrie_et_sante_mentale_2005-2010.pdf.

58. Tarifs. [database on the Internet] 2014 [cited 13/11/2014]. Available from: http://www.ameli.fr/professionnels-de-sante/ medecins/votre-convention/tarifs/index.php.

59. Ricci P, Chantry M, Detournay B, et al. Reimbursed health expenditure of people treated for diabetes: 2001 and 2007 Entred studies. Pratiques et Organisation des Soins. 2010;41(1). http:// fulltext.bdsp.ehesp.fr/Cnamts/POS/2010/1/1.pdf.

60. Fenwick E, Claxton K, Sculpher M. Representing uncertainty: the role of cost-effectiveness acceptability curves. Health Econ. 2001;10(8):779-87.

61. Haute Autorité de Santé (HAS). Valeurs de références pour l'évaluation économique en santé. Revue de la littérature. 2014.

62. Deconinck E, Miadi-Fargier H, Pen CL, et al. Cost effectiveness of rituximab maintenance therapy in follicular lymphoma: long-term economic evaluation. Pharmacoeconomics. 2010;28(1):35-46.

63. Einarson TR, Pudas H, Zilbershtein R, et al. Cost-effectiveness analysis of atypical long-acting antipsychotics for treating chronic schizophrenia in Finland. J Med Econ. 2013;16(9):1096-105.

64. Kolek M, Duba J, Vesela S, et al. Cost-utility analysis of longacting paliperidone in comparison with oral risperidone, oral paliperidone and long long-acting risperidone in the maintenance treatment of schizophrenia in the Czech Republic. Value in Health. 2014;17(7):A459.

65. Citrome L, Kamat SA, Sapin C, et al. Cost-effectiveness of aripiprazole once-monthly compared with paliperidone palmitate once-monthly injectable for the treatment of schizophrenia in the United States. J Med Econ. 2014;17(8):567-76.

66. Olivares JM, Rodriguez-Morales A, Diels J, et al. Long-term outcomes in patients with schizophrenia treated with risperidone long-acting injection or oral antipsychotics in Spain: results from the electronic Schizophrenia Treatment Adherence Registry (eSTAR). Eur Psychiatry. 2009;24(5):287-96.

67. Ascher-Svanum H, Faries DE, Zhu B, et al. Medication adherence and long-term functional outcomes in the treatment of schizophrenia in usual care. J Clin Psychiatry. 2006;67(3):453-60.

68. Kane JM, Detke HC, Naber D, et al. Olanzapine long-acting injection: a 24-week, randomized, double-blind trial of maintenance treatment in patients with schizophrenia. Am J Psychiatry. 2010;167(2):181-9.

69. Achilla E, McCrone P. The cost effectiveness of long-acting/ extended-release antipsychotics for the treatment of schizophrenia: a systematic review of economic evaluations. Appl Health Econ Health Policy. 2013;11(2):95-106.
70. Huguelet $\mathrm{P}$, Khan AN, Morand-Collomb S, et al. Prevalence and characteristics of neuroleptic association in a patient cohort with psychotic disorders. Can J Psychiatry. 2006;51(12):774-82.

71. Abilify Maintena (aripiprazole)—Authorisation details [database on the Internet] 2014 [cited 19/11/2014]. Available from: http:// www.ema.europa.eu/ema/index.jsp?curl=pages/medicines/human/ medicines/002755/human_med_001711.jsp\&mid=WC0b01ac058 $001 \mathrm{~d} 124$

72. Haro JM, Suarez D, Novick D, et al. Three-year antipsychotic effectiveness in the outpatient care of schizophrenia: observational versus randomized studies results. Eur Neuropsychopharmacol. 2007;17(4):235-44.

73. Clinical study report synopsis [database on the Internet] 2014 [cited 10/11/2014]. Available from: https://clinicaltrials.gov/ct2/ bye/uQoPWw41ZXc6edhHld-gWQ7xUXU31B1ymB7gmXNgZd D9jdiudh9k6GgzwU6eBc8uB1glT490dhzzdUV9VLPD1WeKD zqcR48ayUgWi7PxQ7V9gCBWyN6edhHuB7Lzs8gDR4tWRC5 O1WgC8pxE6hB/SVD3FioH5TD3Z6p3WQh8J676NQ7gkB5JdcBJwhGvQ13zwNz5dcxzno3kdhLeihGW6D3edp3WQh8J woyziNHuihzZdp3Z6p3S67gLwUyzdNgznh9NnoP16D3FT7 LEih9mwS3Z6p3FBckeTN9EQoyzdNzk.

74. Di Lorenzo R, Brogli A. Profile of olanzapine long-acting injection for the maintenance treatment of adult patients with schizophrenia. Neuropsychiatr Dis Treat. 2010;6:573-81.

75. Smith M, Hopkins D, Peveler RC, et al. First- v. second-generation antipsychotics and risk for diabetes in schizophrenia: systematic review and meta-analysis. Br J Psychiatry. 2008;192(6):406-11.

76. French Health Insurance (Assurance Maladie). AMELIE - Base des médicaments et informations tarifaires-PLAI $150 \mathrm{mg}$ [database on the Internet] [cited 02/01/2015]. Available from: http://www.codage.ext.cnamts.fr/codif/bdm_it//fiche/index_fic_ medisoc.php?p_code_cip=3400941766930\&p_site $=$.

77. French Health Insurance (Assurance Maladie). AMELIE-Base des médicaments et informations tarifaires - PLAI $100 \mathrm{mg}$ [database on the Internet] [cited 02/01/2015]. Available from: http://www.codage.ext.cnamts.fr/codif/bdm_it//fiche/index_fic_ medisoc.php?p_code_cip $=3400941766879 \&$ p_site $=$.

78. French Health Insurance (Assurance Maladie). AMELIE-Base des médicaments et informations tarifaires - PLAI $75 \mathrm{mg}$ [database on the Internet] [cited 02/01/2015]. Available from: http:// www.codage.ext.cnamts.fr/codif/bdm_it//fiche/index_fic_medisoc. php?p_code_cip $=3400941766701 \& p \_s i t e=$.

79. French Health Insurance (Assurance Maladie). AMELIE-Base des médicaments et informations tarifaires-RLAI $37.5 \mathrm{mg} / 2 \mathrm{ml}$ [database on the Internet] [cited 02/01/2015]. Available from: http://www.codage.ext.cnamts.fr/codif/bdm_it//fiche/index_fic_ medisoc.php?p_code_cip=3400936249363\&p_site=.

80. French Health Insurance (Assurance Maladie). AMELIE-Base des médicaments et informations tarifaires - Risperidone oral $4 \mathrm{mg}$ [database on the Internet] [cited 02/01/2015]. Available from: http://www.codage.ext.cnamts.fr/codif/bdm_it//fiche/ index_fic_medisoc.php?p_code_cip $=3400938178883 \&$ p_site $=$.

81. French Health Insurance (Assurance Maladie). AMELIE-Base des médicaments et informations tarifaires-ALAI $400 \mathrm{mg}$ [database on the Internet] [cited 02/01/2015]. Available from: http:// www.codage.ext.cnamts.fr/codif/bdm//fiche/index_fic_sp_cip.php? p_code_cip $=3400927721908 \&$ p_menu=FICHE\&p_site $=$.

82. French Health Insurance (Assurance Maladie). AMELIE-Base des médicaments et informations tarifaires-Aripripazole oral $15 \mathrm{mg}$ [database on the Internet] [cited 02/01/2015]. Available from: http://www.codage.ext.cnamts.fr/codif/bdm_it//fiche/index fic_medisoc.php?p_code_cip=3400936407862\&p_site=AMELI.

83. French Health Insurance (Assurance Maladie). AMELIE-Base des médicaments et informations tarifaires-OO $10 \mathrm{mg}$ [database on the Internet] [cited 02/01/2015]. Available from: http://www. 
codage.ext.cnamts.fr/codif/bdm_it//fiche/index_fic_medisoc.php? p_code_cip $=3400939371962 \&$ _p_site $=$.

84. French Health Insurance (Assurance Maladie). AMELIE-Base des médicaments et informations tarifaires-HLAI $5 \mathrm{ml} / \mathrm{inj}$. [database on the Internet] [cited 02/01/2015]. Available from: http://www.codage.ext.cnamts.fr/codif/bdm_it//fiche/index_fic_ medisoc.php?p_code_cip=3400932635108\&p_site $=$.

85. French Health Insurance (Assurance Maladie). AMELIE-Base des médicaments et informations tarifaires-Clozapine $100 \mathrm{mg}$ [database on the Internet]. Available from: http://www.codage. ext.cnamts.fr/codif/bdm_it//fiche/index_fic_medisoc.php?p_code_ cip $=3400935704719 \& p \_s i t e=$.

86. PARKINANE LP $5 \mathrm{mg}$ : summary of product characteristics [database on the Internet] 2011 [cited 19/11/2014]. Available from: http://agence-prd.ansm.sante.fr/php/ecodex/frames.php? specid=66238671\&typedoc $=$ R\&ref=R0189092.htm.

87. LEPTICUR $10 \mathrm{mg}$ : summary of product characteristics [database on the Internet] 2014 [cited 19/11/2014]. Available from: http:// agence-prd.ansm.sante.fr/php/ecodex/frames.php?specid=666318 17\& typedoc $=$ R\&ref $=$ R0144737.htm.

88. AKINETON L.P. $4 \mathrm{mg}$ : summary of product characteristics [database on the Internet] 2006 [cited 19/11/2014]. Available from: http://agence-prd.ansm.sante.fr/php/ecodex/frames.php? specid $=66782153 \&$ typedoc $=$ R\&ref $=$ R0131797.htm.

89. Druet C RC, Romon I, Assogba F, Bourdel-Marchasson I, et al. Echantillon national témoin représentatif des personnes diabétiques, Entred 2007-2010. Institut de veille sanitaire. 2012:8. http://www.invs.sante.fr/Publications-et-outils/Guides/Echantillonnational-temoin-representatif-des-personnes-diabetiques-Entred2007-2010

90. Haute Autorité de Santé (HAS). Recommandation de bonnes pratiques-Surpoids et obésité de l'adulte: prise en charge médicale de premier recours. 2011. 